\title{
Carbon nanotubes and their polymeric composites: the applications in tissue engineering
}

\author{
Boyang Huang ${ }^{1}$ (D)
}

Received: 2 March 2020 / Accepted: 29 September 2020 / Published online: 10 October 2020

(c) The Author(s) 2020

\begin{abstract}
Carbon nanotubes (CNTs), with unique graphitic structure, superior mechanical, electrical, optical and biological properties, has attracted more and more interests in biomedical applications, including gene/drug delivery, bioimaging, biosensor and tissue engineering. In this review, we focus on the role of CNTs and their polymeric composites in tissue engineering applications, with emphasis on their usages in the nerve, cardiac and bone tissue regenerations. The intrinsic natures of CNTs including their physical and chemical properties are first introduced, explaining the structure effects on CNTs electrical conductivity and various functionalization of CNTs to improve their hydrophobic characteristics. Biosafety issues of CNTs are also discussed in detail including the potential reasons to induce the toxicity and their potential strategies to minimise the toxicity effects. Several processing strategies including solution-based processing, polymerization, melt-based processing and grafting methods are presented to show the 2D/3D construct formations using the polymeric composite containing CNTs. For the sake of improving mechanical, electrical and biological properties and minimising the potential toxicity effects, recent advances using polymer/CNT composite the tissue engineering applications are displayed and they are mainly used in the neural tissue (to improve electrical conductivity and biological properties), cardiac tissue (to improve electrical, elastic properties and biological properties) and bone tissue (to improve mechanical properties and biological properties). Current limitations of CNTs in the tissue engineering are discussed and the corresponded future prospective are also provided. Overall, this review indicates that CNTs are promising "next-generation" materials for future biomedical applications.
\end{abstract}

\section{Introduction}

The aim of tissue engineering is to restore, repair and replace damaged and diseased tissues with incorporation of biological substitutes such as living cells, biomolecules, biocompatible and degradable synthesis or natural materials that can restore, maintain and enhance the function of tissues or organs [1]. Currently therapies for tissue regeneration involve the utilization of isolated cells or cell substrates, the delivery of tissue-induced biomolecules such as proteins, drugs and oligonucleotides, and finally artificial constructs with or without bio-macromolecules [2,3]. The engineered constructs approach is the most commonly used technique for tissue engineering. Among them, developing biocompatible and bioactive biomaterials is critically essential for tissue engineering. In the past decades, a great development

Boyang Huang

boyang.huang@manchester.ac.uk

1 School of Mechanical, Aerospace and Civil Engineering, University of Manchester, Manchester, UK has been achieved with different novel biomaterials with aid of stem cells and growth factors to mimic the intrinsic architecture and physiochemical properties of the target extracellular matrix (ECM) which plays a significant role in providing appropriate physical and biological atmosphere and supporting cellular interactions including proliferation, migration, differentiation and eventually formation of new tissues. Natural or synthetic polymers have been extensively investigated due to their good biocompatibility and biodegradable properties. However, some polymers and their relative inert nature limited their uses in the tissue engineering. Therefore, combining with other bioactive materials to produce comprehensively enhanced composite materials has become one of trends to develop biomaterials for tissue engineering.

Carbon nanotubes (CNTs), firstly developed by Lijima in 1991 [4], have been widely used for sports applications, microelectronics, photovoltaics and energy storage due to their exceptional mechanical, optical and electrical properties [5-7]. Multiple studies investigated the use of CNTs for biomedical applications. Due to their exceptional electrical 
properties, CNTs are widely used for a biosensor $[8,9]$ and their spectroscopic properties make them interesting materials for photothermal therapy or medical imaging [8]. Moreover, due to their extremely high aspect ratio, CNTs are widely used as nanocarrier to deliver drugs, genes, and other therapeutic agents, by binding them to the sidewall of CNTs through $\pi$-stacking interactions between the graphitic structure and the aromatic nucleotide bases and nucleic acid [10-12]. More recently, the use of CNTs has been explored for tissue engineering applications. The incorporation of CNTs into a polymer matrix displays a variety of structural and physiochemical reinforcement characteristics, including the improvement of strength, flexibility and biocompatibility, induction of angiogenesis, reduction of thrombosis and manipulation of gene expression for tissue repair [13]. This paper provides a comprehensive review on the use of CNTs for tissue engineering applications. Main physical, chemical and biological properties are discussed. The use of compatible materials based on polyester and CNTs is detailed and the use of these materials for neural, cardiac and bone tissue repair and regeneration discussed.

\section{Structure and properties}

CNTs consisting of carbon atoms in a series of condensed benzene rings are cylindrical nanostructures with extremely high aspect ratio. They can be classified as single-walled carbon nanotubes (SWCNTs) and multi-walled carbon nanotubes (MWCNTs) [11]. SWCNTs are long-hollow structures with one-atom-thick walls, where carbon atoms are connected with hexagonal $\mathrm{sp}^{2}$ hybrid bonds. MWCNTs have multi-layers of graphitic carbon tubes, concentrically surrounding a central CNT. The diameter of SWCNTs is normally around $1 \mathrm{~nm}$ to $2 \mathrm{~nm}$ while the diameter of MWCNTs ranges between $10 \mathrm{~nm}$ to100 nm with length varying from $50 \mathrm{~nm}$ to $1 \mathrm{~cm}[14,15]$. The structure of SWCNTs comprises tips and sidewalls. Three distinct tubular structures caused by the orientation of rolling up a graphene sheet can be identified: armchair, zigzag and chiral, which is denoted by the chiral indices (n, m) (Fig. 1a) [16]. The differences between chiral angle and diameter lead to different structures and different properties. The armchair CNTs share similar electrical properties to metals, while the zigzag and chiral CNTs present similar properties to semiconductors $[11,17]$.

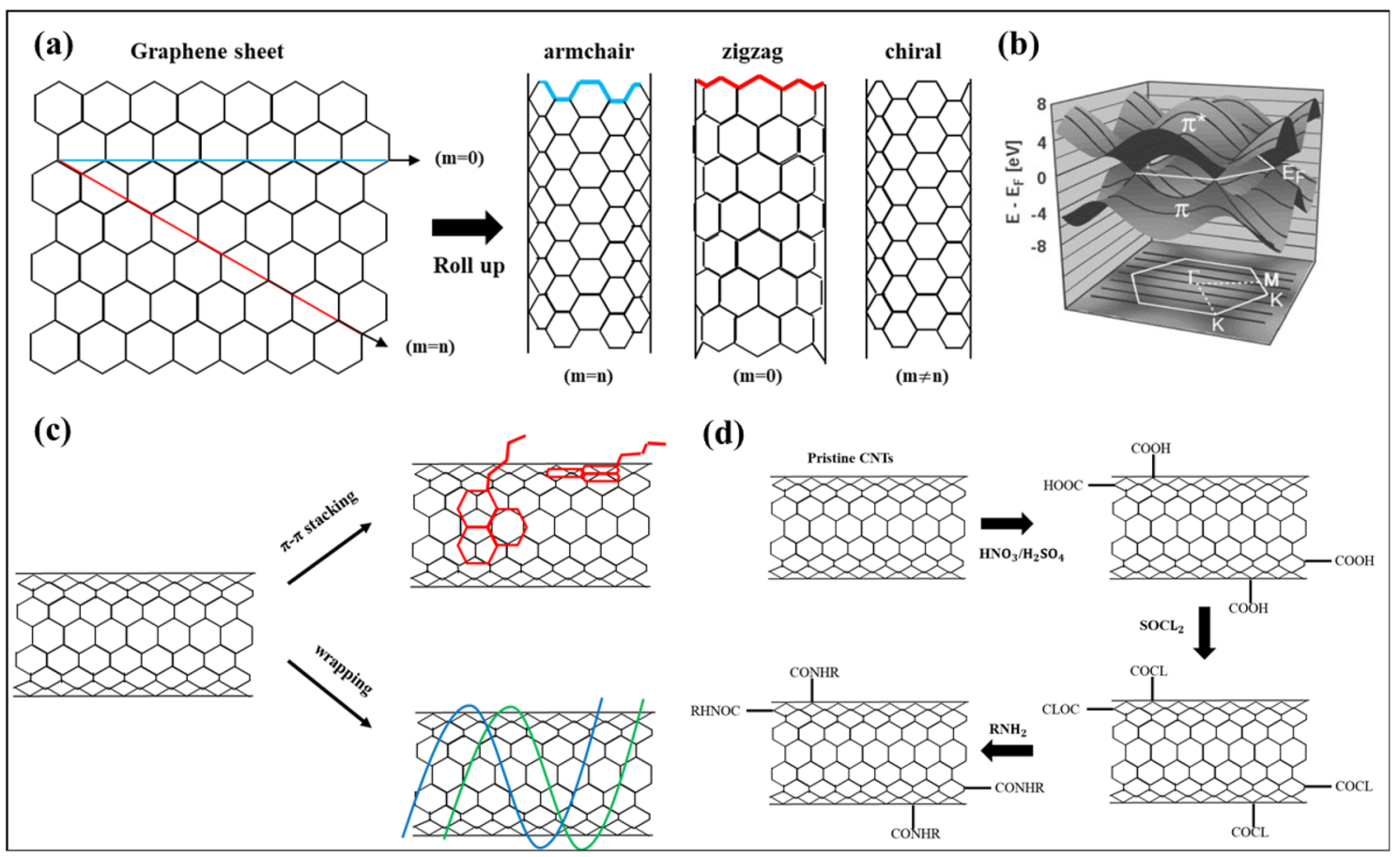

Fig. 1 a Depiction of SWCNTs with armchair, zigzag and chiral structures; b schematic illustration of the CNT band structure and the hexagonal shape of its first Brillouin zone; $\mathbf{c}$ two non-covalent approaches to functionalize of CNTs; d schematic of covalent functionalization of pristine CNTs (reproduced from refs. [16, 26]) 


\section{Physical properties}

SWCNTs and MWCNTs have exceptional mechanical properties, presenting a Young's Modulus in the range of $0.27-1.34 \mathrm{TPa}$ and a tensile strength in the range of 11-200 GPa [18-22]. CNTs also exhibit excellent electrical conductivity as high as $10^{4} \mathrm{~S} / \mathrm{cm}^{2}$ and exceptional thermal conductivity as high as $5000 \mathrm{Wm}^{-1} \mathrm{~K}[13,23,24]$. The electrical structure and electrical properties of CNTs can be deduced from the electrical properties of the graphene sheet [25]. As shown in Fig. 1b, the $\pi$ and $\pi^{*}$ state are joined at six points, called Fermi point, in a hexagon shape. In the $r-\mathrm{k}$ directions (six directions passing through the Fermi points), the electrons are free to move and the graphene sheet behave like a metal. In the other directions ( $\mathrm{r}-\mathrm{M}$ direction), electrons are prohibited by a semiconductor-like band gap and the graphene behaves as a semiconductor [26].

\section{Chemical properties}

The carbon atoms in CNTs are connected by strong nonpolar covalent bonds. The hydrophobic nature of the CNTs surface makes them insoluble in water and most organic solvents. Additionally, strong Van de Waals forces and high aspect ratio often result in the agglomeration of CNTs [27]. Therefore, the homogeneous dispersion of CNTs remains one of main challenges related to the use of CNTs, weakening the mechanical, electrical and chemical properties. To address this problem, functionalized CNTs have been intensively studied. Two commonly used approaches are based on the non-covalent (physical adsorption) and covalent functionalizations (chemical bond) [28, 29].

The non-covalent strategy is a relatively simple process performed under mild conditions based on physical bonding due to different adsorption forces, such as Van de Waals force, hydrogen bonds, electrostatic force and $\pi-\pi$ interactions [28-31].Therefore, the perfect graphitic structure and the electronic properties remain intact. Two non-covalent functionalization methods can be considered (Fig. 1c). One method is based on wrapping surfactants or polymer chains on the sidewalls of CNTs and the second method is achieved through $\pi-\pi$ stacking interactions between aromatic rings of grafted materials and $\pi$-electrons of graphitic sheets on the surface of CNTs [17, 32]. The grafted surfactants or the polymer can behave as a dispersing agent to strengthen the solubility of CNTs in aqueous solutions [33, 34]. Noncovalent strategies create CNTs with high affinity with biomolecules like DNA, RNA, peptides, proteins and enzymes, making them interesting carrier materials to deliver these biomolecules to target cells or organs [34-38].

The covalent approach is based on the formation of covalent linkage between functional groups and the main body of CNTs (Fig. 1d). The defective carbon atoms on the sidewalls or at the end of both SWCNTs or MWCNTs can be oxidized by strong oxidants (e.g. $\mathrm{HNO}_{3} / \mathrm{H}_{2} \mathrm{SO}_{4}$ ), generating carboxylic acid groups or carboxylated fractions [17,37]. In order to further increase the reactivity of CNTs, allowing the attachment of hydrophilic molecules, the carboxylic acid groups are normally converted into acid chloride and then undergo an esterification or amidation reaction $[28,39,40]$. Numerous molecules, including polymers, metals, biomolecules, are reported to be grafted to the surface of carboxylated CNTs. You et al. [41] showed that different kinds of aqueous soluble ionic polymer chains, such as cationic polymers (e.g. poly(2-(dimethylamino)ethylmethacrylate), anionic polymers (e.g. poly(acrylic acid) and zwitterionic polymers (e.g. poly(3-(N-(3-methacrylamidopropyl)- $N, N$-dimethyl) ammoniopropane sulfonate)), can be easily connected to the surface of MWCNTs via surface reversible addition-fragmentation chain transfer (RAFT) polymerization, presenting good solubility. Prabhavathi et al. [42] reported that zinc (II) and copper (II) complexes of mesotetra(4-aminophenyl)porphyrin (Zn-TAP and Cu-TAP) were successfully covalently grafted to the MWCNTs improving their solubility in many solvents. Redondo-Gomez et al. [43] described the biomimetic functionalization of MWCNT surface with cholic acid. After functionalization, MWCNTs showed facial bioamphiphilic behaviour, improving the dispersion stability in aqueous, organic polar and low-polarity solvents. Covalent functionalization strengthens the processability and functionality, being a more stable and robust method compared to the non-covalent approach. However, a disturbance of the nanotube structures ( $\pi$ networks) might result in significant changes in both physical and chemical properties [28, 44]. To address this problem, Nosek et al.[44] covalently grafted bipyridyl ligands directly onto the sidewall of the SWCNT, followed by addition of several different transition metals to form organometallic complexes, instead of using linker molecules between the ligands and the nanotubes. This technique allows tuning the electrical properties through reversing doping in charge transport between the substrates and SWCNTs. The physiochemical properties are summarised in Table 1.

\section{Biological properties}

\section{Cellular interactions}

The use of CNTs for biomedical applications and in particular for tissue engineering requires the understanding of the effects of CNTs at a cellular level, especially the mechanisms of uptake and eliminations of CNTs [45]. The mechanism of cellular internalization for CNTs can be categorized into active (energy dependent) and passive (energy independent) diffusion processes (Fig. 2). The active pathway of CNTs through cellular membranes mainly occurs by endocytosis. 
In the endocytic process, CNTs are internalized inside vesicles (endosomes) prior to being directly transported to the lysosomes localized in the perinuclear compartment of cells [45, 46]. Cui et al. [47] investigated the uptake behaviours of SWCNTs using murine macrophage cells. Selective inhibitions of endocytosis pathways showed that the internalization of SWCNTs involves several pathways, such as macropinocytosis, caveolae-mediated endocytosis and clathrin-dependent endocytosis. Results suggest that the macropinocytosis is the main mechanism of SWCNT internalization and the clathrin-mediated endocytosis is length dependent and relatively important for internalizing the shorter length of CNTs. Phagocytosis, another type of endocytosis, allows the uptake of over $1 \mu \mathrm{m}$ length CNT. The phenomenon involves the participant of macrophages and is an energy-dependent pathway not possible to occur at low temperature [45, 48-50]. The energy-dependent endocytosis is strongly dependent upon the temperature and the presence of metabolic inhibitors. Shi et al. [51] reported that the low temperature $\left(4^{\circ} \mathrm{C}\right)$ and the presence of inhibitors significantly hindered the internalization of CNTs. Results also show that CNTs penetrate the cell membrane first through tip. For nanotubes with end caps or carbon shell at their tips, the uptake process involves tip recognition through receptor binding, rotation, driven by asymmetric elastic strain at the tube-bilayer interface, and finally enter the cell in the nearvertical direction. For nanotubes without caps and shells on their tips, tip-entry mode will not occur.

Passive diffusion of CNTs, as an energy-independent process, is not affected by both temperature and the presence of endocytosis inhibitors [45, 52]. The interaction between CNTs and cells starts with CNTs contacting with cell membranes and follows by a sequence of events such as landing on the cell membrane surface, penetrating into the lipid head group of phospholipid bilayer membrane and eventually sliding through the lipid tails [53, 54]. Pantarotto et al. [52] proved that functionalized SWCNTs can cross the cell membrane, accumulate in the cytoplasm and reach the cell nucleus. During the process, the endocytosis uptake mechanism was not triggered and CNTs behaved like cell penetrating peptides and related synthetic oligomers, piercing into the cell membrane and reaching to the cell nucleus, due to their positive charge and the presence of amino acid sequences as signal for nuclear localization. Similarly, Lacerda et al. [55] used chemically functionalized MWCNTs to investigate the uptake mechanism in the presence of different well known cellular uptake inhibitors at different temperatures. Results showed that the internalization of CNTs does not occur by one single pathway but through the combination of pathways. It was also possible to observe that 30 to $50 \%$ of functionalized MWCNTs enter cells by a temperature-insensitive and energy-independent mechanism. The remaining functionalised MWCNTs enter 


\section{Endocytosis}

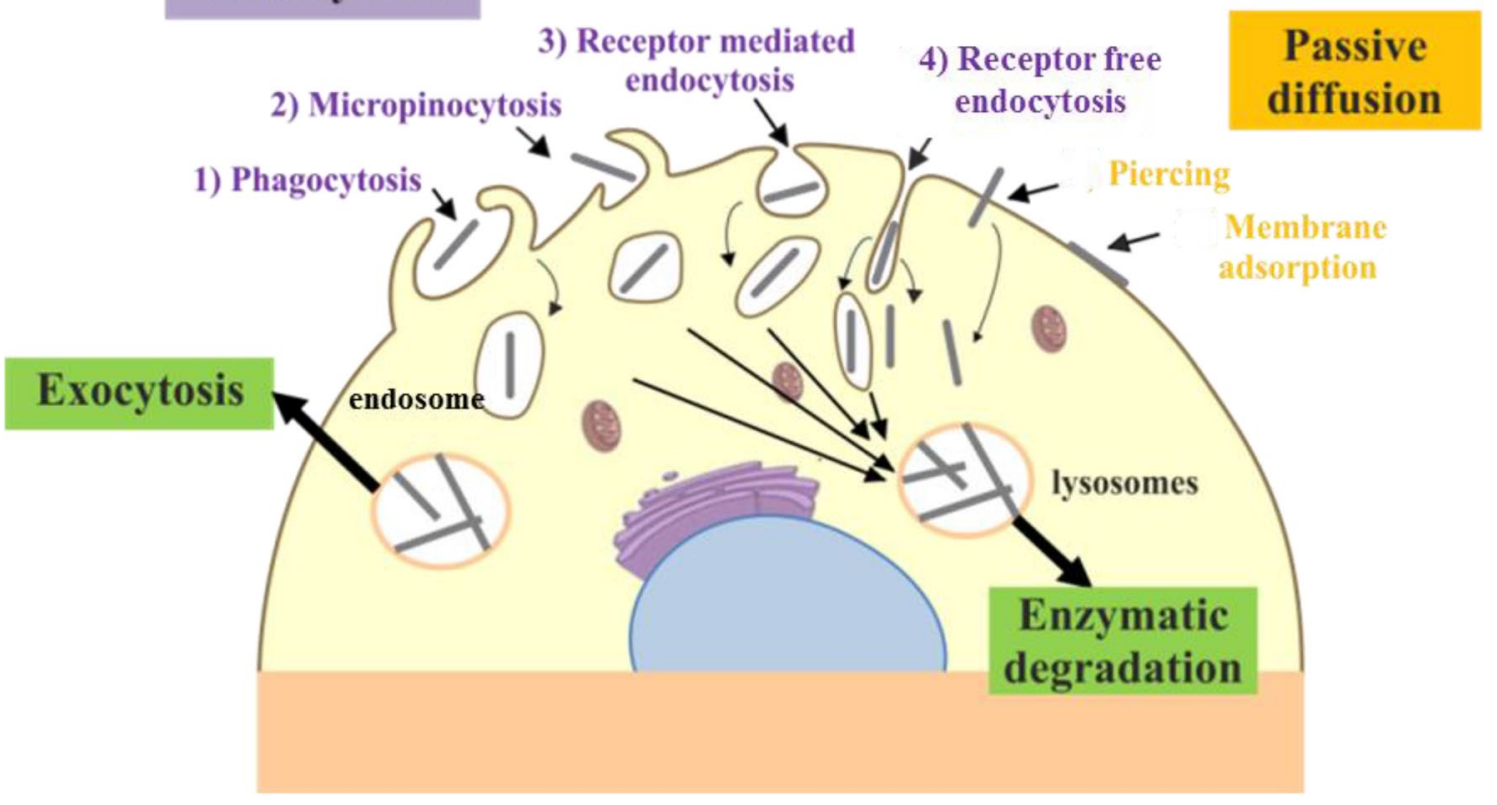

Fig. 2 Cellular uptake mechanisms for CNTs (reproduced from $[45,56,57]$ )

the cells penetrating into the cytoplasm through an energy dependent active mechanism.

The elimination of CNTs involves exocytosis and enzymatic degradation processes. It has been reported that CNTs are expelled from cells through exocytosis after several hours or days of internalization. Neves et al. [58] found that double wall carbon nanotubes, functionalized by wrapping RNA around the nanotube wall, were taken up by cultured cells and released after $24 \mathrm{~h}$ with no discernible stress response. However, the dwell time can be prolonged through loading cytocompatible materials. Mao et al. [59] showed that collagen grafted SWCNTs presented no negative cellular effects and a large amount of CNTs was internalized by cells. The internalized CNTs were distributed in the perinuclear region and retained in the cells for more than one week. Contrarily, exocytosis can be triggered by the cell stress conditions. As shown by Marangon et al. [60] human monocyte macrophages and endothelial cells can release microvesicles containing CNTs under stress conditions. This mechanism removes the exogenous and cytotoxic carbon nanomaterials by inducing the formation of autophagic microvesicles [45, 61]. Recently, some researchers also found that CNT can be enzymatically degraded within the cells. Sato et al. [62] implanted tangled oxidized MWCNTs (t-ox-MWCNTs) into rat subcutaneous tissues and found that the majority of the large aggregations of CNTs remain unchanged while small agglomerations were observed inside the macrophages, where they are gradually degraded in lysosomes. Goode et al. [63] investigated the interactions between microglial cells and MWCNTs in both extra and intracellular situations. Using dynamic, live cell imaging and high-resolution imaging techniques, they found that microglial cells can break apart and internalize micro-sized extracellular agglomerates of acid oxidized MWCNTs (AO MWCNTs). After $2 \mathrm{~h}$ of exposure to MWCNTs, N9 microglia were washed to remove unbound MWCNTs. After further $2 \mathrm{~h}$ of incubation, MWCNTs were observed at the plasma membrane. After $24 \mathrm{~h}$, high-resolution images show the presence of MWCNTs in the microglia cytoplasm. From these images, it was possible to observe that AO MWCNTs were different stages of structural breakdown (highly disordered graphitic structures and delamination of the outer walls), indicating possible intracellular biodegradation.

\section{Biocompatibility}

Cytotoxicity effects of CNTs strongly depend on their physio-chemical characteristics such as length, diameter, surface area, tendency for agglomeration, and the presence and nature of catalyst residuals generated during the fabrication process of CNTs [64]. These characteristics are schematically represented in Fig. 3.

\section{Dimensions}

CNTs exist in the form of compact tangles considered as particles [62] or in the form of long, straight needle-like "fibres" [65-68]. Depending on their dimensions, different 


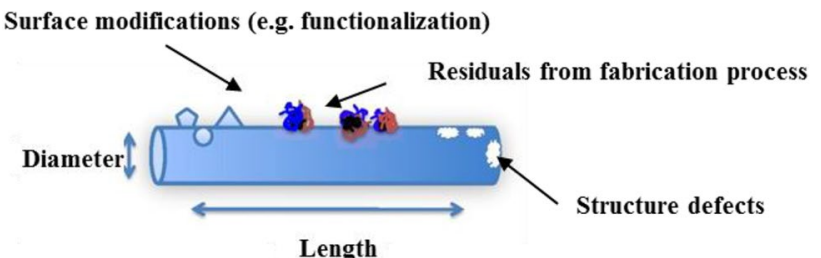

Fig. 3 Schematic illustration of several factors that might cause CNTs toxicity

effects can be obtained, for example, particle like nanotubes can lead to fibrosis and cancer while needle-like nanotubes can affect the pleura [64]. Murphy et al. [65] reported that CNTs presented similar length-dependent pathogenicity as asbestos. Their research work showed that long CNTs can reach the pleura of mice from the air being retained at the parietal pleura, which results in the inflammation. Xu et al. [66] conducted a similar study in rats. Two different sizes of MWCNTs were chosen for the study, including a larger sized needle-like MWCNT (MWCNT-L) and a smaller sized cotton candy-like MWCNT (MWCNT-S). Results showed that the MWCNT-L presented higher risk of causing asbestoslike pleural lesions and the MWCNT-S presented stronger inflammation leading to higher 8-hydroxydeoxyguanosine levels in the lung tissue. Boyles et al. [67] showed that long MWCNTs are cytotoxic, potentially inducing pro-inflammatory and pro-fibrotic immune response. However, short CNTs present insignificant effects on the respiratory burst and reduction in phagocytic ability. Recently, Zhang et al. [68] investigated the effects of different width sizes (30 to $400 \mathrm{~nm}$ ) of SWCNTs and MWCNTs. The results showed that the cellular uptake of macrophages depends upon CNT size, especially on the widths of their bundles. The uptake linearly increases with the width size, leading to increase cytotoxicity. These studies seem to indicate that the toxicity of CNTs is length-dependent, increasing with the increase of the dimensions of CNTs.

\section{Impurity}

Three strategies are used to synthesize CNTs: arc discharge, laser ablation and chemical vapour deposition $[1,11$, 69-71]. Chemical vapour deposition (CVD) is the mostly widely used approach. In this case, reaction with a metal catalyst and hydrocarbon source occurs at a temperature higher than $700{ }^{\circ} \mathrm{C}$ using fluidized bed reactors that allow uniform gas diffusion and heat transfer [1, 72]. The lengths of the CNT, varying from nanometres to millimetres and the widths ranging from 1 to $100 \mathrm{~nm}$, strongly dependent on the reaction conditions [1]. The CVD method provides large scale production with reduced costs, high yield, less energy consumption and less waste production [73]. However, the metal catalysts such as iron, nickel, cobalt and molybdenum can be deposited on the outside surface of the nanotube, which might induce some cytotoxicity effects due to oxidative stress and anti-oxidant depletion [74-77]. Therefore, for biomedical applications, a purification step such as air oxidation, acid refluxing and surfactant based sonication is required [78]. However, the purification process is a costly step and the structures of CNT might be altered during the process [1].

\section{Surface characteristics}

Structure defects and imperfections of the CNT framework are considered one of the reasons causing toxicity. Muller and Fenoglio reported that the presence of structural defects of CNTs could trigger acute pulmonary toxicity and genotoxicity [79, 80]. Recently, Jiang et al. [81] found that the structural defects of MWCNTs can be correlated with cell membrane damage. In this work, positively/negatively charged giant unilamellar vesicles (GUVs) and supported lipid bilayers (SLB) were used as a model of cell membrane. Results showed that negatively charged MWCNTs defects tend to bind and disrupt the cationic sites of the model membrane, being expected a similar behaviour in the case of cell plasma membrane.

Due to the CNTs intrinsic inert physio-chemical properties and incompatibility with nearly all solvents, a great effort has been taken to modify the surface characteristic, covalently and non-covalently grafting different functional groups or biomolecules. This also mitigates the toxicity of CNTs. Liu et al. [82] compared the toxicity effects of both pristine MWCNTs and carboxylated MWCNTs on a human normal liver cell line L02. The authors found both pristine MWCNTs and carboxylated MWCNTs reduce the electrical potential of mitochondrial membrane, enhance the release of cytochrome c, and eventually activate the mitochondria mediated apoptotic pathway. Functionalized MWCNTs showed milder effects, suggesting the reduced toxicity effects on L02 cells. Jain et al. [83] also reported that acid oxidized carboxylated CNTs with shorter lengths, hydrophilic surfaces and high aqueous dispersibility present less toxic effects than the pristine counterparts. The decreased bioactivity and pathogenicity of functionalized MWCNTs were also reported in vivo [84]. Recently, Allegri et al. pointed out that the mitigation effects of carboxyl- or aminofunctionalized MWCNTs can be partially attributed to the tendency to generate larger agglomerates in protein-rich biological fluids [85]. However, the functionalization might still cause some toxicity due to the formation of reactive oxygen species (ROS) which could induce oxidative stress caused by the presence of redox-active groups [86]. Zhang et al. [87] compared the non-functionalized MWCNTs, functionalized MWCNTs with carboxylation (MWCNTs-COOH) 
and functionalized MWCNTs with polyethylene glycol (MWCNT-PEG) in terms of their toxicity effects on macrophage. Results revealed that MWCNTs-COOH produces a significant increase in ROS, interrupts the ATP synthesis, and activate both the MAPK and NF-kB signalling pathways, which in turn upregulates $1 \mathrm{~L}-1 \beta, 1 \mathrm{~L}-6, \mathrm{TNF}-\alpha$, and iNOS to trigger cell death. Similarly, Lucia et al. [88] compared the cytotoxic, genotoxic/oxidative and inflammatory effects of three types of commercial available CNTs including pristine MWCNTs, $-\mathrm{OH}$ and $-\mathrm{COOH}$ functionalized MWCNTs. Results showed that functionalized MWCNT presented higher cytogenotoxicity and -OH functionalized MWCNTs showed no membrane damage and induction of oxidative DNA damage. For pristine MWCNTs, an inflammatory response was observed. Similar researches were observed by Zhou et al. [89]. The authors compared pristine and functionalized $(-\mathrm{OH},-\mathrm{COOH}) \mathrm{MWCNTs}$ in terms of cytotoxicity and genotoxicity and found that pristine MWCNTs induced high cell death than functionalized MWCNTs that caused greater DNA oxidation. The interactions between CNTs and proteins are also highly relevant. It is known that when nanoparticles enter in a physiological environment, they are able to rapidly absorb biomolecules such as proteins and enzymes, forming a bio-corona that can alter the size and interfacial composition of the nanomaterials, leading to a change of biological "identity" (new biological responses and structural or functional modification due to the biomolecules present in the corona) $[64,90]$. Several researches showed that this protein corona is able to minimize the toxic effects of CNTs. Ge et al. [91] showed that the $\pi-\pi$ stacking facilitate the binding of SWCNTs with aromatic residues (Trp, Phe, Tyr) of blood proteins. However, the protein absorption by nanoparticles is both protein-- and CNT-specific. Lu et al. [92] studied the effects of three different types of functionalized SWCNTs (carboxylated, hydroxylated and amined SWCNTs) on human serum albumin (HSA) and found that the absorption capability of HSA increases as follows: caboxylated SWCNTs > hydroxylated SWCNTs $>$ amined SWCNTs. Moreover, the results showed that coating carboxylated CNTs with HAS significantly reduced their cytotoxicity in comparison of other two types of SWCNTs. Shannahan and co-workers [93] studied different types of CNTs including unmodified and carboxylated SWCNT and MWCNTs (SWCNT-COOH and MWCNT-COOH), polyvinylpyrrolidone (PVP)-coated MWCNT and nanoclay. SWCNT-COOH and MWCNT-COOH were found to bind the greatest amount of proteins. Modified carboxylated CNTs bound a high number of proteins compared to unmodified CNTs, suggesting covalent binding to protein amines. Improved results were observed with SWCNT-COOH. Moreover, modified CNTs bound a high number of specific proteins (e.g. nuclear receptor coactivator-6, lactase-phlorizin hydrolase) implying hydrogen bonding and electrostatic interactions were involved in the protein corona formation. PVP coating of MWCNTs did not influence the composition of the protein corona, further strengthening the possibility of hydrogen bonding and electrostatic interactions. Although the formation of protein corona may alter the toxicity effects of nanoparticles, strong interactions between CNT surface and proteins might induce conformational changes of proteins (i.e. the secondary and tertiary structure of bovine serum albumin) and lead to potential loss of functions [94, 95]. The potential toxicity's effects induced by CNTs are summarised in Table 2.

\section{Processing properties}

As mentioned in previous sections, CNTs are 1D nanomaterials and the internalization of CNTs may induce the cytotoxicity and genotoxicity. Moreover, CNTs are insoluble in water and most organic solvents, making them difficult to directly process to fabricate scaffolds/constructs for tissue engineering applications. Therefore, for the sake of minimizing the potential toxicity and fabrication points of views, they are usually used as reinforcement fillers incorporated with polymeric biomaterials due to the fact that polymers are biocompatible and easily processed by various fabrication techniques. However, there is no universal processing

Table 2 The toxicities caused by different physio-chemical properties of CNTs

\begin{tabular}{|c|c|c|}
\hline Characteristics & Toxicity’ effects & Refs \\
\hline Dimensions & $\begin{array}{l}\text { Needle-like shape of CNTs may cause pleural lesions and inflammation; Longer and larger CNTs } \\
\text { showing greater cytotoxic }\end{array}$ & [65-68] \\
\hline Impurities & Residuals such as iron, nickel, cobalt and molybdenum may induce oxidative stress and anti-depletion & [74-77] \\
\hline Surface defects/imperfections & $\begin{array}{l}\text { Structural defects may trigger acute pulmonary toxicity and genotoxicity; Defect sites on MWCNTs } \\
\text { correlate with their interaction with membranes }\end{array}$ & [79-81] \\
\hline Functionalization & $\begin{array}{l}\text { Debatable; the addition of functional group may mitigates the toxicity of CNTs. However, the forma- } \\
\text { tion of reactive oxygen species may trigger cell death; Functionalised CNTs may cause cyto-genotox- } \\
\text { icity }\end{array}$ & [82-89] \\
\hline Corona & $\begin{array}{l}\text { The formation of bio-corona leads to a change of biological "identity" which may cause the loss of } \\
\text { functions }\end{array}$ & {$[94,95]$} \\
\hline
\end{tabular}


technique which can be suitable for all situations. The selection of processing technologies has to be depended on the desired properties, chemical compositions, ease of synthesis of composite and cost considerations and it has to trade off some properties for a specific case [96]. In this sense, a brief review is provided to introduce the commonly used processing technologies of CNTs in the polymer matrix for tissue engineering applications.

\section{Solution-based processing}

Solution-based processing is most used technique to produce CNT involved polymer composite due to its easy processing procedure. The dissolved CNTs and polymer matrix solutions in same/different solvents are mixed thoroughly, followed by intensive agitation such as mechanical stirring, sonication, and vigorous shaking. With the solvent evaporation, the composite films/sheets containing CNTs and polymers are formed. The solution-based process is involved in various fabrication techniques, such as electrospinning, freeze-casting, phase separation and extrusion-based additive manufacturing [97-99]. The selection of appropriate processing technology is specifically depended on specific applications. Electrospinning is a widely used fabrication process which can produce fibrous matrix from micro to nano-scale level [100]. More than 75 different natural/synthetic polymers have been electrospun and fabricated as scaffolds/constructs for various tissue applications such as skeletal muscle, bone, skin, blood vessel and neural tissues [101]. The electrospinning technique is specifically attractive to the CNTs involved polymeric composite scaffolds due to the fact that this technique is able to create highly orientated fiber mats [102]. The alignment of CNTs in the polymer matrix creating anisotropic scaffolds can further strengthen the electrical conductivity, mechanical properties and their biological properties [103-105]. Freeze-casting, also referred to ice-templating, is a solidification process to produce porous structures. When suspensions or solutions are solidifying, walls are templated due to the rejection of particles and porous structures are created after post-solidification, replicating the morphology of the solidified fluid [106]. Freeze-casting can be used to produce both anisotropic and isotropic structures while anisotropic characteristics are more extensively investigated since anisotropy of scaffolds plays a vital role in tissue engineering [107]. The capability of producing high porous and anisotropic structures makes freeze-casting appealing to fabricate and mimic the native bone tissue incorporating with CNTs to strengthen their mechanical properties and biological properties. Phase separation is also able to produce porous structures where the dissolved polymer solution is placed in a mould followed by the crystallization of the solvent and the solvent is removed by freeze drying process, leaving behind the pores with a morphology similar to that of solvent crystallinities [108]. The pores can be controlled by crystallization rate and $\mathrm{PH}$ value [109]. Although these methods are able to fabricate porous polymer/CNTs scaffolds for various tissue engineering applications, they usually do not enable to properly control pore size, pore geometry and spatial distribution of pores, besides being almost unable to construct internal channels within the scaffold. In this sense, the additive manufacturing techniques are considered to be a viable alternative to fabricate 3D porous scaffolds. Gonçalves et al. [99] reported a 3D printed polycaprolactone/hydroxyapatite/ multi-walled carbon nanotubes (PCL/HA/MWCNTs) scaffolds for bone tissue engineering. $50 \mathrm{wt} \% \mathrm{PCL}, 40 \mathrm{wt} \% \mathrm{HA}$ and $10 \mathrm{wt} \%$ MWCNTs were mixed thoroughly in dichloromethane solution and printed using a pressure-assisted $3 \mathrm{D}$ printing. Fully interconnected porous 3D scaffolds were successfully produced with pore size ranging between 450 and $700 \mu \mathrm{m}$. Ho et al. [110] also reported the use of pressure-assisted 3D printing to produce 3D porous scaffolds for cardiac tissue regeneration. Different amount of functionalized CNTs ( $1 \mathrm{wt} \%, 3 \mathrm{wt} \%$ and $5 \mathrm{wt} \%$ ) were mixed with PCL in chloroform solution. The interconnected channels were uniformly distributed with filament widths ranging from 300 to $450 \mu \mathrm{m}$ and pore sizes ranging from 425 to $675 \mu \mathrm{m}$.

\section{Polymerization processing}

The key factor of solution-based processes which can successfully produce CNTs involved polymer composite is to de-bundle the CNTs agglomeration and ensure homogeneous dispersion in the polymer matrix. As mentioned in previous sections, CNTs are insoluble in most organic solvents. Although, the functionalized CNTs facilitate their solubility in the solvents, the slow evaporation of solvent and following fabrication process might spend long time, leading to CNTs re-agglomeration and resulting in the inhomogeneous dispersion in the polymer matrix. Therefore, alternative methods which is able to process insoluble CNTs and ensure uniformly distribution are required. In-situ polymerization is a construct strategy in which the monomers or pre-polymers can mixed with functionalized CNTs or monomer-grafted CNTs, followed by the polymerization carried out by adjusting the temperature and time $[96,111,112]$. This method allows a strong interaction between polymer matrix and CNTs by the covalent linkage or the non-covalent linkage. Kateklahijani et al. [113] fabricated poly (anilineboronic acid) (PABA) nanocomposite containing DNA-functionalized carbon nanotubes (DNA_CNT) and nitrogen-doped graphene (NEG) through in situ chemical polymerization. It was found that DNA_CNT_NEG presented a good predispersion in the 3-aminophenylboronic acid monomer solution and able to create highly-ordered and poly-conjugated structure with superior electrical conductivity $(14,300 \mathrm{~S}$ 
$\mathrm{m}^{-1}$ at $3.0 \mathrm{wt} \%$ filler content). Bonab et al. [114] reported a comparative study of thermoplastic polyurethane (TPU) containing linear CNTs and branched CNTs using in-situ polymerization. They found that the composite containing branched CNTs formed stronger networks than the linear CNTs composite, presenting better mechanical properties. Moreover, the use of branched CNTs enables the rheological threshold at much lower concentration for branched CNT nanostructures than the linear CNT ones.

Gelation, also called sol-gel transition, is a process that links macromolecular chains, resulting in the formation of a branched polymer structures [115]. It can be divided into physical gelation in which strong physical gels present strong bounds between chains, whereas weak gels have reversible links formed by temporary associations between chains. In contrast, chemical gelation forms covalent bounds, resulting in a stronger gel formation [116] and this process involves the polymerization process.

The polymerization process can be achieved by adding the chemical crosslinkers. Han et al. [117] integrated an electro-conductive hydrogel containing polyvinyl alcoholborax (PVAB) and carbon nanotube-cellulose nanofiber (CNT-CNF) nano hybrids using the chemical gelation process where the cellulose nanofiber (CNF) served as a dispersant to uniformly stabilize CNTs in the suspensions. The CNT-CNF solutions were added by borax and polyvinyl alcohol (PVA) and borax solutions, followed by the cooling gelation to form the CNT-CNF/PVAB composite gels. The CNT-CNF/PVAB composite gel presents high compressive modulus $(\sim 93 \mathrm{kPa})$ and storage modulus $(\sim 7.12 \mathrm{kPa})$ and assembled CNT-CNF/PVAB supercapacitor presents a specific capacitance of $117.1 \mathrm{~g}^{-1}$ and a capacitance retention of $96.4 \%$ after 1000 cycles. Ravanbakhsh et al. [118] developed a glycol chitosan/CNT-based composite hydrogels for vocal fold tissue engineering in which glycol chitosan acted as the matrix, glyoxal served as the chemical crosslinker, and carbon nanotubes (CNTs) were added as the reinforce fillers. The composite hydrogels were extensively tested by scanning electron microscopy, rheological analysis and cell viability analysis. The authors found the porosity was increased with the increase of concentration of carboxylic CNTs and the gelation time and the storage modulus were as function of CNT concentration.

Ultraviolet (UV) initiator photo-polymerization is also a usually used method to synthesize hydrogels containing CNTs. Polat et al. [119] developed a gelatin-based conductive hydrogels doped with carbon nanotube (CNT), poly(3,4-ethylenedioxythiophene):poly(styrenesulfonate) (PEDOT:PSS) and silver (Ag) nanoparticle separately. Gelatin (Gel) and methacrylic anhydride (MA) were used to synthesize the gelatin methacrylate. Irgacure 2959 was used as a photo-initiator and poly(ethylene glycol) diacrylate (PEGDA) was used to increase mechanical strength. The
CNT, PEDOT:PSS and Ag were used as conductive fillers. The results showed that the porosity was significantly decreased by adding these conductive nanoparticles while the thermal stabilities was improved compared than nonconductive GelMA hydrogels. Equivalent impedance measurements showed that the conductive hydrogels exhibited high impedance at low frequencies and low impedance at high frequencies. Ahadian et al. [120] reported an elastomeric polymer/CNT scaffolds for cardiac tissue engineering using the photo-polymerization. CNTs were dispersed in the poly(ethylene glycol) dimethyl ether porogen and mixed with poly(octamethylene maleate (anhydride) 1,2,4-butanetricarboxylate) (124 polymer) pre-polymer. The mixture was molded into shape and crosslinked by UV light. The 124 polymer scaffolds containing $0.5 \mathrm{wt} \% \mathrm{CNTs}$ presented improved excitation threshold $(3.6 \pm 0.8 \mathrm{~V} / \mathrm{cm})$ compared to the one with $0.1 \mathrm{wt} \% \mathrm{CNTs}(5.0 \pm 0.7 \mathrm{~V} / \mathrm{cm})$ and the one without CNTs $(5.1 \pm 0.8 \mathrm{~V} / \mathrm{cm})$, suggesting the greater tissue maturity.

Moreover, the addition of CNTs into polymer-based hydrogel can improve the viscoelastic behavior of composite hydrogels, making them capable of maintaining the shape fidelity. This makes them attractive to develop as a bioink and process as 3D construct using additive manufacturing. Nurly et al. [121] developed a polyethylene glycol (PEG) and polyvinyl alcohol (PVA) double network (DN) hydrogel containing different contents of CNTs $(0.125 \mathrm{wt} \%, 0.25 \mathrm{wt} \%$ and $0.5 \mathrm{wt} \%$ ). Followed by mixing the first network of PEGdiacrylate with PVA solutions and CNTs, the DN network was formed by the crosslinking reaction catalyzed by adding ammonium persulfate (AP). The developed hydrogels were then tested in terms of their printability. The results showed that the CNTs additional were capable to maintain the shape memory effect of hydrogels and the viscoelasticity for printability was improved as function of CNT concentration. Li et al. [122] developed a hybrid bioink containing gelatin, sodium alginate and carbon nanotubes and used direct 3D printing technique to produce blood vessel construct. After rapid fabrication, the vessel constructs were immersed in the calcium chloride solution to acquire adequate cross-linking reaction. The results showed that the bionic circular tubes with an average wall thickness of $0.5 \mathrm{~mm}$ and a length of $7-10 \mathrm{~cm}$ were successfully fabricated and the addition of CNTs can significantly improve the mechanical properties. No cytotoxicity effects were observed.

\section{Other processing technologies}

Other fabrication processes to obtain polymeric scaffolds containing CNTs includes coating CNTs on the surfaces of pre-formed scaffolds and the melt-based processing. Various coating techniques can be used to coat CNTs on the produced polymer scaffolds such as layer-by-layer assembly 
(LBL) and electrophoretic deposition (EPD). Patel et al. [123] using LBL deposition coated different amounts of CNTs $(0.5 \mathrm{wt} \%$ and $1 \mathrm{wt} \%)$ onto the surface of electrospun PCL fibers and investigated the in-vivo responses of scaffolds. They found the PCL matrix coated with CNTs significantly reduces the inflammatory signs, substantially promotes angiogenic responses and accelerates the bone tissue healings. Fraczek-Szczypta et al. [124] used EPD technique coating graphene oxide (GO) and polyaniline (PANI) nanocomposite onto the surface of titanium (Ti) substrates for neurite regeneration. Four different coatings including GOTi-GO, GO:PANI (1:1), GO:PANI (4:1), and GO:PANI (16:1) were extensively characterized such as morphology, microstructure, surface energy, wettability and biological tests. Among the four different coatings, GO:PANI (16:1) coating is the most promising one which presents better cell viability and facilitates the formation of 'neurosphere-like' structures of cortical neurons. The CNTs surface coating can change the surface characteristics and have direct impacts on the cell-material interactions. However, the limitations are also co-existed such as the limited effects on the overall properties of the scaffolds (i.e. mechanical property) and reduced long-term functionality caused by the removal of coating layers (i.e. degradation of polymer). Melting process is also used to fabricate the polymer/CNTs scaffolds. This method is usually applied to prepare the mixture of thermoplastic polymers and CNTs particles. The moltenstate polymer matrix, when applied the air pressure or the mechanical strength, can generate high shear forces which can facilitate the de-agglomeration of CNTs bundles and assist their homogeneously dispersion in the polymer matrix. In our group previously researches $[125,126]$, we successfully used melt blending to prepare PCL/MWCNTs composite and PCL/HA/MWCNT composite. The composites were processed to be $3 \mathrm{D}$ porous scaffolds for bone tissue applications using the screw-assisted extrusion additive manufacturing. The produced scaffolds exhibit stronger mechanical properties and enhanced osteogenesis. The combination of screw motion can significantly promote the CNTs alignment in PCL matrix. The fibrous-like CNTs embedded by nanoscale HAs highly mimic the native structures of bone tissue. Although melt process is a straightforward and simple method to produce polymer/CNTs composite and the fabrication process is free from toxic solvents, the limitation of this technique is also apparent due to the CNTs agglomeration. Although the screw motion, to some extent, de-bundles the CNTs agglomerations and benefits the homogeneous dispersion, we are still able to observe the agglomerated CNTs by the transmission microscopy (TEM) and the polarised Raman microscopy. Moreover, with the increase of concentration of CNTs (up to $3 \mathrm{wt} \%$ ), a significant change of rheological behaviour of molten composite occurred and a strong phase transition from liquid-like to solid-like state occurred, which seriously hinders the use of higher contents of CNTs and the printing process.

\section{Applications of carbon nanotubes in tissue engineering}

\section{Neuronal tissue engineering}

Nerve loss/damage may arise from external trauma, anoxia, hypoglycaemia, diabetes and virus infection [13]. Although nerve axons are able to regrowth, the damage size is limited to $5 \mathrm{~mm}$ and coaptation is always needed to surgically join the damaged nerve ends. Therefore, a variety of nerve therapies have been developed including coaptation, nerve autograft, nerve allograft and nerve conduit [127]. Any strategy which is used to repair the damaged central nervous system (CNS) cannot avoid addressing the regeneration of axons, the plastic remodelling of neuronal circuitry, and the regeneration of neurons which are arisen from stem cells [128-130]. However, this is a very complex issue. Axons growth needs to overcome unfavourable and inhibited environment, and requires proper axonal spatial organization, target recognition and the rebuild of functional synapses. Stem cells are required to be alive and able to differentiate into a specific neuronal lineage [13]. Therefore, the design of any treatment for damaged nerves has to take into account all these steps. In this perspective, the synthetic materialbased implants such as artificial scaffolds are required to provide biocompatible and bioactive environment, allowing the attachment, maintenance, and differentiation of nerve cells and eventually inducing the formation of functional neuronal assembly [130-132]. Furthermore, the platform provided for nerve regeneration needs to have appropriate dimensions to avoid any nerve damage and compression and to allow the release of neurotrophic factors and diffusion by the proximal site of axon injury [133]. Flexibility is crucial to allow in vivo manipulation, requiring appropriate ultimate tensile strength and elastic modulus $(1.4$ and $0.58 \mathrm{MPa}$ respectively for decellularised nerve tissue) [134-136]. Eventually, Nanotopography is of great importance since the interaction of neurons with their growing substitutes occurs in nanoscale level such as neural cell adhesion molecules-NCAM,N-cadherin and integrins which are extremely sensitive to the nanoatmosphere of substrates [137, 138]. A variety of researches has been reported in terms of directly using CNTs as substrates for neuronal tissue engineering and results showed that CNTs are able to support neurons attachment, facilitate a generation of longer and more elaborate neurite and also promote cell differentiation [139-141]. However, the potential toxicity of CNTs in biological system and the difficulty of producing a regulated 2D/3D structures strictly restricted the utilization of CNTs as a substrate for 
neural tissue engineering. Polymeric scaffolds, although providing a biocompatible environment, are lack of electrical conductivity and appropriate tensile strength, limiting the applications of electrically propagating tissue. However, the combination of CNTs with high electrical conductivity and extraordinary mechanical properties might provide an alternative pathway for these non-conductive materials in the neuronal tissue engineering and meanwhile minimize the toxicity effect of CNTs.

Due to the exceptional electrical conductivities, extensive studies have investigated the combination of CNTs with biocompatible polymers to develop 2D electrical conductive meshes or membranes for neural tissue engineering. Vicentini et al. [142] used three types of carbon nanostructures containing factionalized graphene, MWCNTs and nanohorns as fillers to develop a poly ( $\mathrm{L}$-lactic acid) composite material with carbon loadings over a range between $0.1 \mathrm{wt} \%$ to $5 \mathrm{wt} \%$ and used electrospinning to create a $2 \mathrm{D}$ film for neural tissue engineering. The composite material containing MWCNT showed overall higher Young's modulus and elongation break but lower electrical resistance. All these composite scaffolds showed good biocompatibility and support the proliferation of human neuronal precursor cell line SH-SY5Y. Shao et al. [143] reported a novel strategy to create a membrane containing CNTs and poly(dimethyldiallylammonium chloride) (PDDA) via layer-by-layer assembly. Interestingly, results showed that positively charged PDDA and negatively charged CNTs could lead to more homogeneous dispersion of CNTs in the polymer matrix. The developed substrates provided a potent regulatory signal over neural stem cells in terms of adhesion, proliferation, differentiation, outgrowth and electrophysiological maturation of neural stem cells derived neurons. Moreover, authors proposed a possible mechanism that the integrin-mediated interactions between the substrates and neural stem cells (NSCs) activated focal adhesion kinases (FAK), leading to initiation of a series of signalling events such as MAPK signalling pathway which regulates NSCs differentiation, a Wnt signalling pathway which regulates NSCs proliferation and a PI3K-AKT signalling pathway to regulates the cell survival (Fig. 4).

Wu et al. [144] investigated the use of biocompatible chitin/carbon nanotubes (Ch/CNT) composite hydrogels produced by blending CNTs with chitin solution in sodium hydroxide/urea solution with a ratio of $11 \mathrm{wt} \%: 4 \mathrm{wt} \%$ and regenerating in ethanol. $\mathrm{Ch} / \mathrm{CNT}$ hydrogels showed higher tensile strength than pristine chitin hydrogel (2.09 $\mathrm{MPa}$ and $0.73 \mathrm{MPa}$ respectively) and elongation at break while the swelling ratio decreased. Moreover, cell studies with Schwann cells showed that the ch/CNT substrate presented no cytotoxicity and neurotoxicity. Results also showed an increase of proliferation, adhesion and spreading body with cells presenting large extension and elongation. This trend was more evident with increasing the concentration of CNTs and culture time. Similarly, Liu et al. [145] developed

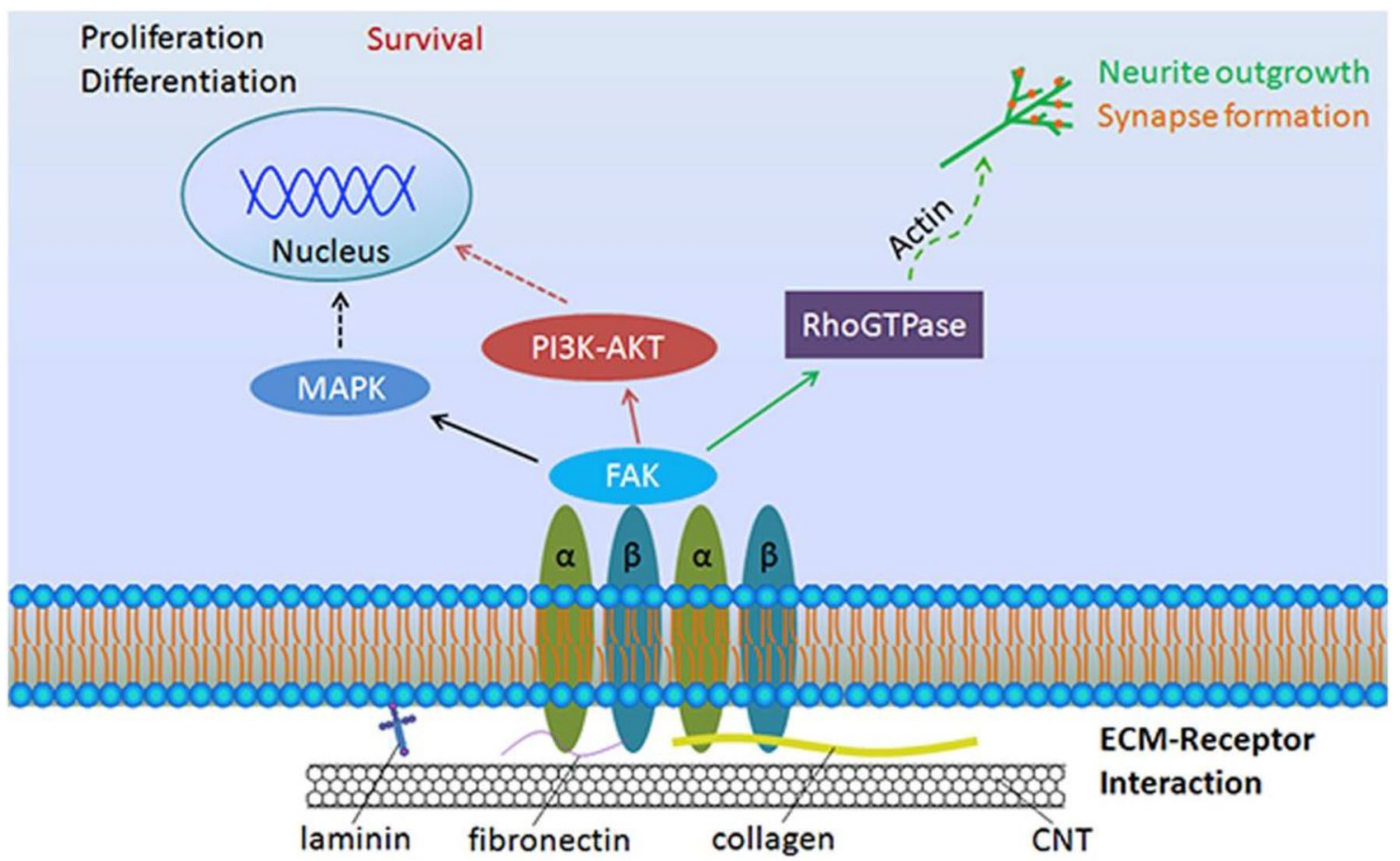

Fig. 4 Schematic figure showing ECM proteins absorbed on CNT multilayers interacts with integrin, activate signaling transduction pathways and thus regulates NSCs biological processes (Ref. [143]) 
a composite hydrogel containing crosslinkable graphene oxide acrylate (GOa) and carbon nanotube poly(ethylene glycol) acrylate(CNTpega), also referred to rGOa-CNTpega-OPF hydrogel produced by in situ chemical reduction in L-ascorbic acid solution. The incorporation of graphene oxide and CNT increases the electrical conductivity and PC 12 cell proliferation. Fluorescence microscopy images showed robustly stimulation of neural cells on the composite hydrogel.

Arslantunali et al. [136] designed a MWCNT/ poly(2hydroxyethyl methacrylate) (pHEMA) composite conduit to improve peripheral nerve regeneration. Results show that the incorporation of MWCNT improved both the mechanical properties (elastic modulus of $0.32 \pm 0.06 \mathrm{MPa}$ ) and electrical conductivity $\left(8 \times 10^{-2} \Omega^{-1} \mathrm{~cm}^{-1}\right)$. SHSY5Y neuroblastoma cells were used to investigate the biocompatibility of the composite conduit. No cytotoxicity effects were observed. Salehi et al. [146] developed a conduit containing polylactic acid (PLA), MWCNT, and gelatin nanofibris with coating the recombinant human erythroprotein-loaded chitosan. The physical properties including a compressive modulus of $2.66 \pm 0.34 \mathrm{Mpa}$, the ultimate tensile strength of $5.51 \pm 0.13 \mathrm{Mpa}$ and electrical conductivity of $0.32 \mathrm{~S} \times \mathrm{cm}^{-1}$ with the porosity of $85.78 \pm 0.7 \%$ were reported. Degradation tests showed $11 \mathrm{wt} \%$ losses after 60 days compared to PLA conduits $(8.6 \pm 0.62 \mathrm{wt} \%)$. After two weeks of SCs cell culture, no cytotoxicity was observed. In vivo tests were conducted by implanting the conduits seeded with $1.5 \times 10^{4}$ Schwann cells (SCs) into a $10 \mathrm{~mm}$ sciatic nerve defect created in Wistar rats showing that the produced conduit had comparable potential to the autograph. Ahn et al. [147] reported the in vivo study of CNT-interfaced glass fiber scaffold used as a nerve conduits for the repair of transected rat sciatic nerve (Fig. 5a). Functionalized CNTs were successfully covalently grafted onto the surface of aligned phosphate glass microfibers (PGFs) and then the composites containing CNTs and PGFs were placed into three dimensional poly (L/D-lactic acid) (PLDLA) tubes, following implanted into $10 \mathrm{~mm}$ gap of a transected rat sciatic nerve. After sixteen weeks of in vivo test, the number of regenerating axons crossing the scaffolds, the cross-sectional area of the re-innervated muscles and the electrophysiological findings were significantly strengthened by the use of CNTs. Recently, Xia et al. [148] reported the use of a multivalent polyanion-dispersed CNT to construct electrospun fibrous scaffold for nerve tissue regeneration (Fig. 5b). In the work, CNTs are non-covalently functionalized by hyperbranched polyglycerol sulfate, followed by coating onto electrospun Polycarprolactone (PCL) nanofibers. Results showed that the scaffolds not only served as a biocompatible platform for pluripotent stem cells (IPS) to adhere and proliferate, but also induce higher IPS differentiation. Moreover, the aligned fibres can guide the orientation of generated neurites.

Instead of using 2D membranes or 1D conduit obtained through labour-intensive methods, frequently requiring the use of toxic organic solvent, the use of additive manufacturing (3D printing) to create $3 \mathrm{D}$ constructs is becoming highly relevant.

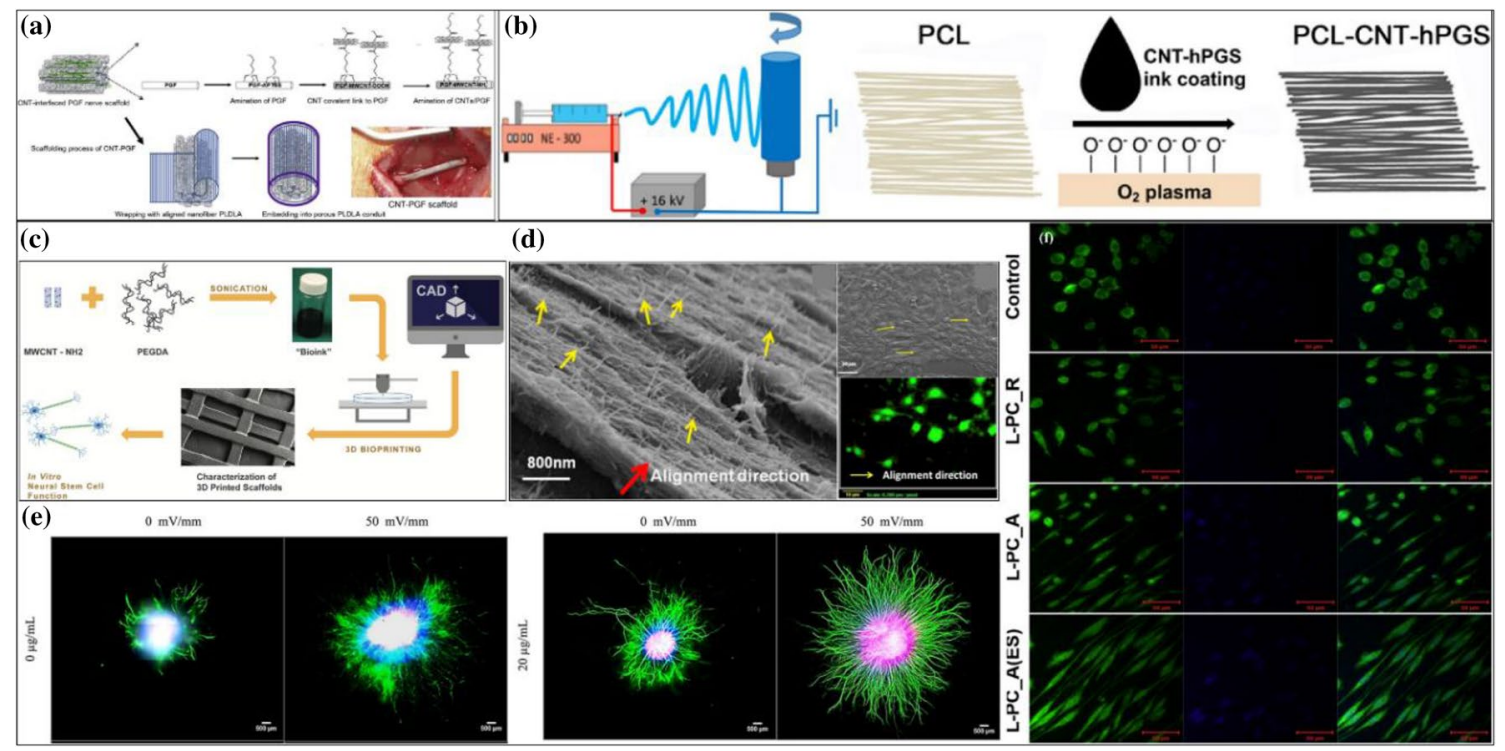

Fig. 5 a 1D PLDLA/CNT conduits for nerve regeneration showing fabrication process and representative results of in vivo test; $\mathbf{b}$ Fabrication process of 2D electrospun PCL-CNT-hPGS PLGA/MWCNT mesh; c Schematic diagram showing the fabrication process of 3D porous MWCNT composite scaffold; $\mathbf{d}$ Alignment of MWCNT inside chitosan matrix and aligned cell distribution; e Neurite outgrowth with/without SWCNT and with/without electrical stimulation; f Fluorescence images of PC12 cells cytoskeleton on different scaffolds (ES: with electrical stimulation) (reproduced from Refs. [147, 148, $150,152,153]$ 
Serrano and co-workers [149] produced 3D porous scaffolds containing MWCNTs and chondroitin sulphate (CS), a major regulatory component of the nerve tissue, via freezecasting. The developed scaffolds allowed the formation of neural networks and displayed calcium transients and active mitochondria, even without coating poly-D-lysine (PL). According to the authors, this behaviour can be explained by a synergistic neural-permissive signalling that arise from both the scaffold structure and its MWCNTs and CS components, suggesting that these scaffolds are suitable to implant in the acute phase after injury as it is during this phase that the most critical sequence of events took place to drive either nerve regeneration or fibrogial scar formation.

Lee et al. [150] used a vat-photopolymerization system to produce amine functionalized MWCNTs and PEGDA composite scaffolds (Fig. 5c). Cell proliferation and differentiation studies were performed using NSCs, with and without electrical stimulation $(500 \mu \mathrm{A})$. Results showed that vat-polymerization allowed the fabrication of complex $3 \mathrm{D}$ structures with controlled microarchitecture and porosity. PEGDA/MWCNT scaffolds promoted neural stem cell proliferation and early neural differentiation compared to scaffolds without MWCNTs. Electrical stimulation promoted neural maturity assessed by protein expression analysis. Results suggested that the PEGDA/MWCNT composite scaffolds coupled with electrical stimulation might have a synergistic effect on improving neural outgrowth in nerve tissue engineering.

It has been also reported that the alignment of CNTs in the polymeric matrix can improve the mechanical properties, electrical conductivities and the biological characteristics of neural substrates. Gupta et al. [151] compared aligned MWCNT/ chitosan scaffolds with randomly distributed MWCNT/chitosan composite scaffolds and found that the elastic modulus, yield strength and ultimate tensile strength for aligned scaffolds were increased $12.7 \%, 21.9 \%$ and $11.2 \%$ respectively. Alignment of MWCNTs introduced highly anisotropic electrical conductivity (100,000 times higher) along its direction, as compared to the transverse direction of the scaffold. Shrestha et al. [152] developed a self-electrical stimulated double-layered nerve guidance conduit (NGC) for nerve tissue engineering (Fig. 5d). The produced NGC consists of chitosan grafted polyurethane with functionalized MWCNTs and a layer of coated polypyrrole and its structure is formed by an aligned inward layer and a randomly oriented outer layer. The results showed a significant improvement in the adhesion, proliferation and differentiation of both PC 12 cells and Schwann cells. Moreover, it was possible to observe better distribution of cells along the aligned fibers.

Recently, numerous interests has been addressed in the use of electrical stimulation applying to the conductive biomaterials such as CNT enhanced scaffolds since it could provide a stronger guidance and stimulation for the neural cells ingrowth. Koppes and his co-workers [153] mixed caboxylated SWCNTs with hydrogels to produce composite scaffolds applied by direct current stimulation (Fig. 5e). With increasing the loading of SWCNTs, the electrical conductivity was significantly improved and the neurite outgrowth has been significantly improved compared to the SWCNT-free controls. Furthermore, with applying electrical stimulation, SWCNT-loaded materials presented a 7.0-fold increase in outgrowth relative to the unstimulated, nanofiller-free controls. However, the mechanism of neurite extension was still required further investigation of nanofiller properties.

Similarly, Wang et al. [154] found that the use of electrical stimulation enhances the neurite extension. They produced poly (lactic-co-glycolic acid) (PLGA) composite scaffolds with a mixture of carboxylated MWCNTs and a coating of poly-L-lysine which was used for enhancing hydrophilicity (Fig. 5f). Scaffolds with aligned fibers were produced to guide PC12 cells and DRG neurons growing along the fiber direction. Results showed that with an electrical stimulation of $40 \mathrm{mV}, \mathrm{PC} 12$ cells and DRG neurons showed longer neurite length. Differentiation of PC12 cells also increases due to the electrical stimulation.

\section{Cardiac tissue engineering}

The treatment of myocardial damage represents a significant health problem due to the increased number of population suffering from cardiovascular diseases (CVDs) [155]. Common treatments involve surgical approaches, the use of left ventricular assistance devices (LVAD), pharmacological and gene therapies [156]. However, these treatments present several limitations such as the lack of donated organs, thrombosis, infection, bleeding, and low clinical efficiency $[155,157-159]$. Gene therapy is a relatively recent treatment, based on the use of a vial virus carrying genes to the targeted cells. However a high fraction of population might be excluded from this therapy due to the presence of antiadeno-associated virus antibody [160]. However, none of these treatments focus on tissue regeneration but on treating the symptoms of cardiac diseases. Therefore, cardiac tissue engineering provides an alternative pathway to overcome these limitations. It is known that the loss of specialized cardiac muscle cells, also known as cardiomyocytes, usually leads to a series of cardiac diseases [155]. Therefore, cardiac cell therapy, the most commonly used cardiac tissue engineering approach, involves the direct implantation of specific cells such as cardiac progenitor cells, pluripotent stem cells and cardiomyocytes derived from these cells into a host heart [161]. Although cardiac cell therapy shows unique advantages over traditional cardiac disease treatments, drawbacks such as low cell seeding efficiency, poor 
survival rate, immunogenic response and lack of integration with host tissue limited the clinical outcome [155, 162]. Cell reprogramming represents a new approach aiming to eliminate some of the problems of the cell therapy but further research is still needed before its clinical applications [162-164].

The use of synthetic materials with or without cells represents another implanted cardiac tissue engineering approach aiming to mimic the myocardium tissue, considering its composition, mechanical and electrical properties and eventually providing the appropriate physio-chemical environment for cardiomyocytes growth. The myocardial extracellular matrix (including collagen, glycoprotein, proteoglycan and glycosaminoglycan etc.) play a significant role in providing the sufficient mechanical strength and the anisotropic organization of myocardium [165]. The connection of cardiomyocytes is achieved by fascia adherences, desmosomes and gap junctions. The fascia, desmosomes and ECM provides $\sim 425 \mathrm{kPa}$ elastic modulus of native heart tissue and the electrical communication between cardiomyocytes occurs in the gap junctions with longitudinally and transversely electrical conductivity of $\sim 0.16 \mathrm{~S} / \mathrm{cm}$ and $\sim 5 \times 10^{-3} \mathrm{~S} / \mathrm{cm}$ respectively [166, 167]. Therefore, biomaterials for cardiac tissue engineering must present sufficient mechanical strength and remain conductive for the growth of myocardium tissue regeneration. Polymeric materials can be biocompatible, but are also usually inert which limits the intercellular interaction and signal transfer and the mechanical properties require further improvements [168-172].

In order to improve both mechanical and electrical conductivity properties of biopolymers, a wide range of polymer/CNTs composites have been investigated. Li et al. [173] prepared poly ( $N$-isopropylacrylamide) (PNIPAAm) hydrogel containing SWCNTs. The hydrogel was lyophilized in order to create solid substrates. In vivo and in vitro tests were conducted to assess the biocompatibility characteristics. In vitro results with brown adipose-derived stem cells (BASCs) showed that the presence of SWCNTs improves the biological performance of PNIPAAm substrates. In vivo studies showed that the PNIPAAm/SWCNTs significantly enhanced the engraftment of BASCs in infract myocardium. Wickham et al. [174] fabricated PCL membranes by solvent casting and meshes by electrospinning both incorporating thiophene-conjugated CNTs (T-CNTs). Biological studies using cardiac stem progenitor cells (CPC) showed that PCL and PCL/T-CNTs membranes, contrary to the corresponding meshes, were not able to support cell attachment and proliferation. In the case of electrospinning meshes, it was possible to observe that the incorporation of T-CNTs increases the mechanical strength and cell proliferation but no effects were observed for cell differentiation. Similarly, Liu et al. [175] produced electrospun poly(lactic-co-glycolic acid)/ MWCNTs. Different amounts of MWCNTs (1, 3, 5 and 7 wt $\%$ ) were considered. Results showed that both the young's modulus and electrical conductivity were significantly higher in the meshes containing $3 \mathrm{wt} \%$ of MWCNTs. Neonatal rat cardiomyocytes seeded on the meshes maintained their viability, induced cell elongation and enhanced sarcomeric $\alpha$-actin and troponin I production in cardiomyocytes.

Current cardiac tissue engineering approaches present insufficient remodelling of the intercalated discs (IDs) connecting the cardiomyocytes. CNTs might contribute to overcome this limitation. Sun et al. [176] developed a CNT/collagen patch to enhance intercalated disc assembly in cardiac myocytes (Fig. 6). In the myocardium, $\beta 1$-integrin plays a significant role as a mechanotransducer activating a host of intracellular signalling pathway, including focal adhesion kinase (FAK), integrin-linked kinase (ILK) and Src [177, 178]. Results not only showed that the composite substrate enhances the cardiomyocyte adhesion and maturation but also promotes ID-related protein expression, enhancing ID formation and functionality. Composite substrates containing CNTs significantly accelerate gap junction formation by activating the $\beta 1$-integrin-mediated FAK/ERK/GATA4 pathway.

The major limitation of using polymeric materials for the repair of heart defects is that the insulated walls hinder the transfer of electrical signals between cardiomyocytes, leading to arrhythmias when the biopolymeric materials is implanted. Shin et al. [179] addressed this problem producing patches for cardiac tissue engineering based on gelatin methacrylate (GelMA) and CNTs (Fig. 7a). GelMA were pre-coated onto CNT bundles and $50 \mu \mathrm{m}$ thick CNT-GelMA hybrid hydrogels was prepared by photo-crosslinking. Porous substrates were prepared and cultured with neonatal rat cardiomyocytes. Results showed that CNT-GelMA presented three times higher spontaneous beating rate, $85 \%$ lower excitation threshold, significantly improving cell adhesion, organization and cell-cell coupling. Mombini et al. [180] used polyvinyl alcohol (PVA), chitosan (CS) and different concentration of CNTs $(1,3$, and $5 \mathrm{wt} \%)$ to produce electrospun cardiac conductive scaffolds. Results showed that nanofiber containing 1 wt\% CNT had optimal physiochemical properties (elastic modulus $130 \mathrm{Mpa}$, electrical conductivity $3.4 \times 10^{-6} \mathrm{~S} / \mathrm{cm}$ ). Biological results showed that scaffold containing $1 \mathrm{wt} \%$ CNT promoted the gene expression of cardiac marker by applying electrical stimulation. Pok et al. [172] prepared a gelatin chitosan hydrogel with SWCNTs that act as electrical nanobridges for communication between cardiomyocytes. Results showed that the composite hydrogels allow to achieve excitation conduction velocities similar to the native myocardial tissue $(22 \pm 9 \mathrm{~cm} / \mathrm{s})$, supporting the cardiomyocytes function. Yu et al. [181] investigated collagen type I and carbon nanotubes seeded with cardiomyocytes (CMs). Results showed that CNT-collagen scaffolds 
Fig. 6 Schematic representative illustrating the effect of CNT composite substrate on the enhance of the intercalated disc assembly (Ref. [176])

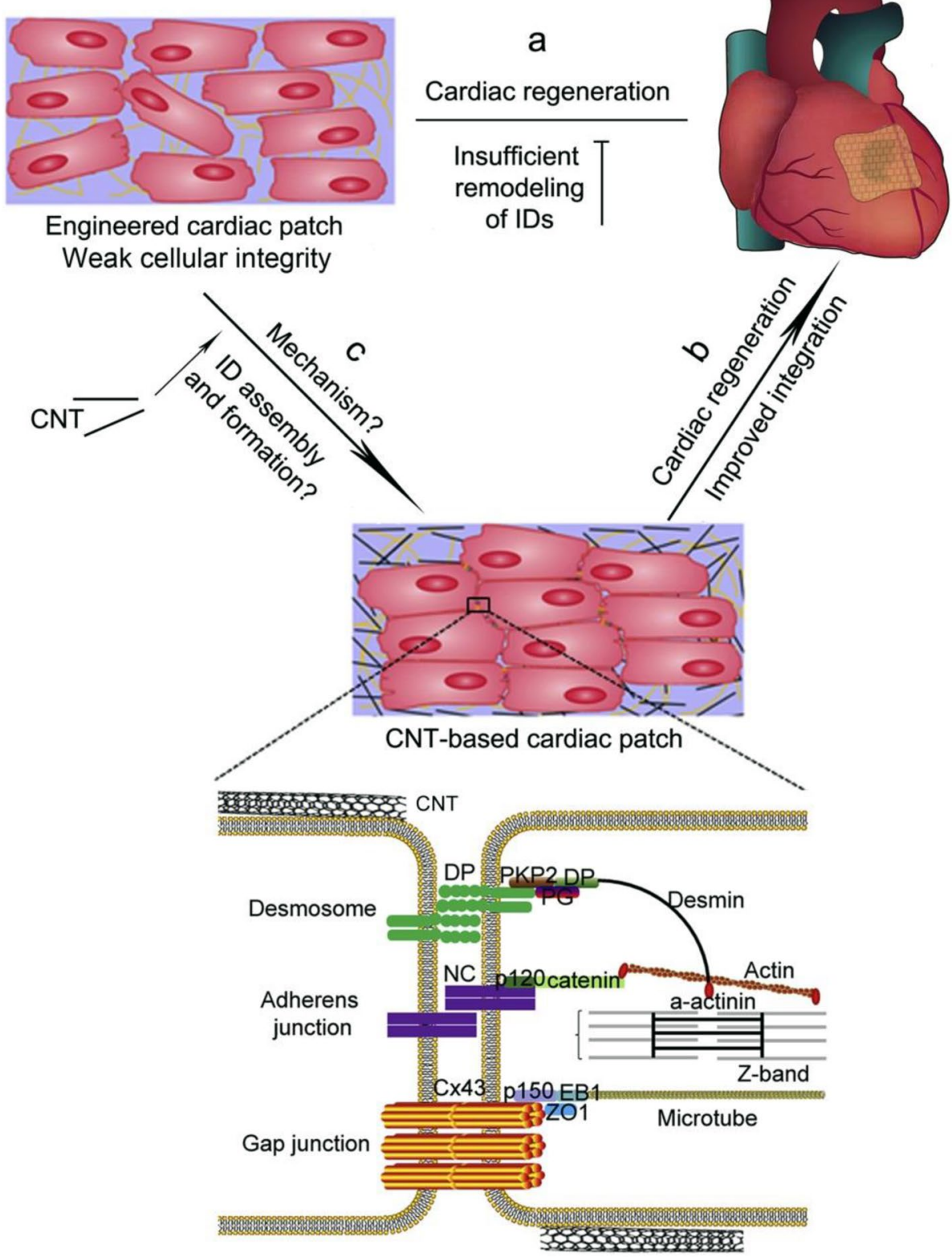

increased rhythmic contraction area, indicating improved CMs functions. Kharaziha et al. [105] used electrospinning to develop a hybrid electrospun composite mesh containing carboxyl acid group functionalized with MWCNTs and aligned poly(glycerisebacate)/gelatin (PG). Different levels of MWCNTs were investigated ranging from 0 to 1.5 wt\%. As observed from the experimental work, electrical and mechanical properties (toughness, tensile strength, and elastic modulus) increased with the increased concentration of MWCNTs (Fig. 7b). Produced meshes were also able to support cardiomyocytes ingrowth. Meshes containing MWCNTs resulted in stronger spontaneous and synchronous beating behaviour with 3.5 -fold lower excitation threshold and 2.8-fold higher maximum capture rate, compared to meshes without MWCNTs.

Besides 2D structures, CNTs, mixed with polymeric materials, have been also used to produce 3D scaffolds. Ho et al. [110] fabricated PCL/MWCNT composite scaffolds using an extrusion-based additive manufacturing system (Fig. 7c). Scaffolds were produced with filament diameters ranging from 300 to $450 \mu \mathrm{m}$ and pore size between 425 and $675 \mu \mathrm{m}$. The incorporation of CNTs not only improved the mechanical properties (e.g. elastic modulus and toughness), but also modified PCL morphology enhancing crystallinity. Biological tests with $\mathrm{H} 9 \mathrm{C} 2$ cells showed no cytotoxicity effects. Results also showed that the addition of MWCNTs 


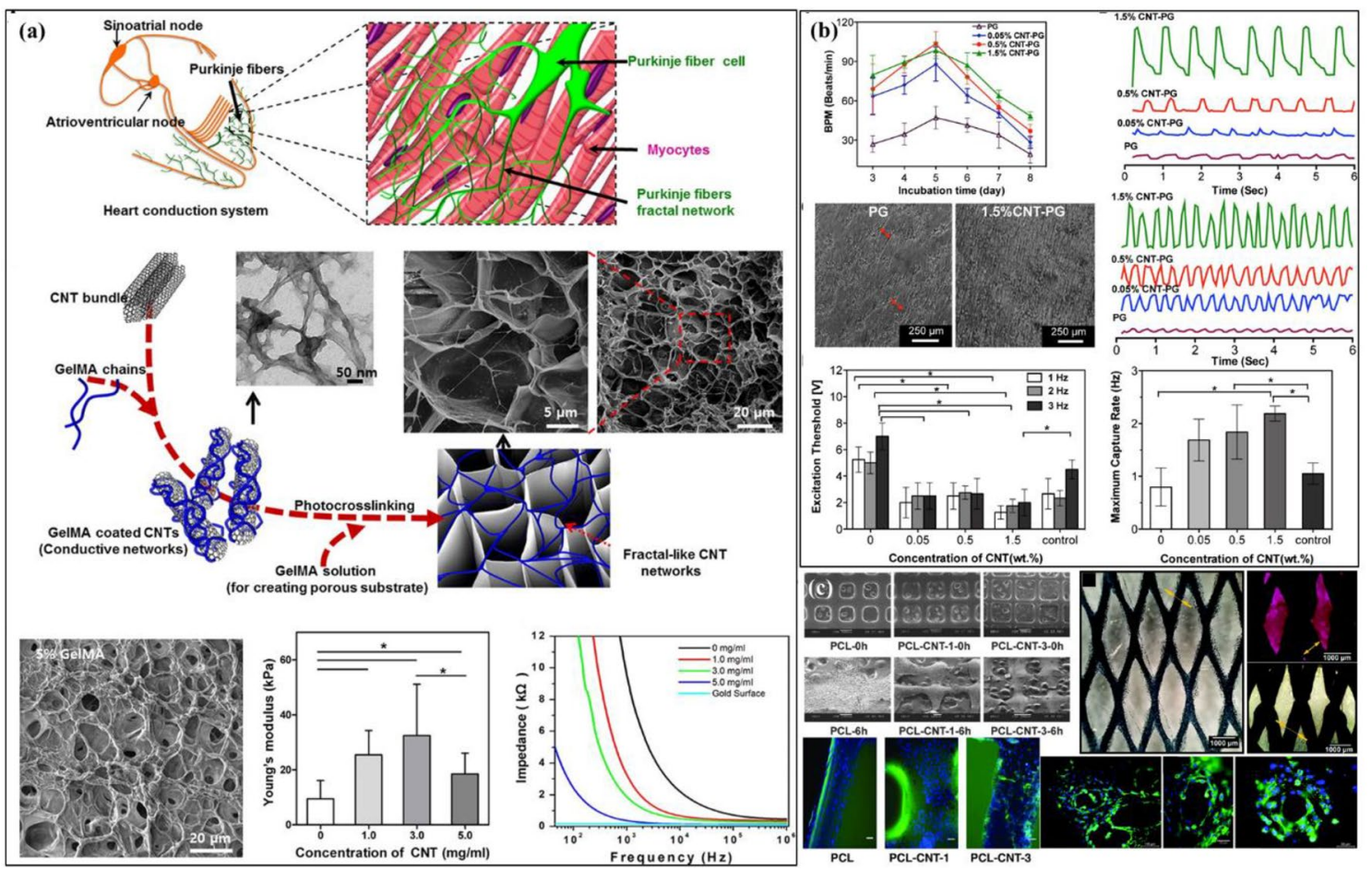

Fig. 7 aCNT-GelMA hybrid hydrogel from synthesis to characterizations including schematic diagram illustrating the isolated heart conduction systems with purkinje fibers, fabrication process and characterizations; b Beating frequency for different CNT composite scaffolds at different culture days; spontaneous contraction patterns for all scaffolds at day 7; phase contrast images showing non-organized tis-

had an impact on the degradable kinetics, slowing down the degradation process. Similarly, Izadifar et al. [182] used a vat-photopolymerization system to produce methacrylate collagen (MeCol) scaffolds with carboxyl functionalized CNTs (Fig. 7c). Cell-laden constructs were produced using human coronary artery endothelial cells (HCAECs) and the irradiation condition (light density of $6.1 \mathrm{Mw} / \mathrm{cm}^{2}$ and irradiation time of $45 \mathrm{~s}$ ) did not have a negative effect on cell viability. The fabricated composite scaffolds also showed improved electrical conductivity and mechanical properties.

\section{Bone tissue engineering}

Bone is a vascular and highly specialized form of connective tissue, which plays a significant role in maintaining the shape of skeleton, protecting the soft tissues in cranial, thoracic and pelvic cavities, transmitting the forces of muscular contraction during movement, maintaining ions and regulating the extracellular matrix (ECM), blood production and blood $\mathrm{pH}$ [183]. Bone is able to heal and remodel itself in the case of limited damage or fracture. However, in pathological fractures, traumatic bone loss or primary tumor resection, where the bone defects exceeds a critical size $(5 \mathrm{~mm})$, bone is no longer able to heal itself [184]. In this case, a variety of sue (red arrow) and aligned tissue on PG and CNT-PG scaffolds; contraction patterns of electrical stimulation for all scaffolds; excitation threshold and maximum capture rate for all scaffolds; $\mathbf{c}$ Degradation of PCL/CNT scaffolds; Fluorescence images of H9c2 myoblast cells; top view of 3D printed CNT/MelCol scaffolds; immunohistochemistry analysis of HCAEC morphology (Refs. [105, 179] [110, 182])

therapies were reported including autografts, allografts and xenografts. However, these methods present several limitations including limited supply and donor site morbidity for autografts, risk of rejection and transmission of diseases for allografts, and risk of immunogenicity and poor clinical outcome in the case of xenografts [185-187]. Therefore, the use of tissue engineered synthetic bone scaffolds, 3D structures that provide the necessary support for cell attachment, proliferation, and differentiation, represents a novel and highly relevant approach.

Bone is a tissue that exhibit piezoelectric properties, meaning that when stresses are applied, the bone produce a current. Piezoelectric materials also exhibit a reverse piezoelectric effect, meaning that when a current is applied, the material compresses. This is an important characteristic that allows accelerating bone tissue regeneration by using electro-active scaffolds and the application of electrical stimulations.

Tanaka et al. [188] fabricated 3D block structure of CNTs and investigated the efficiency as scaffold materials for bone repair, comparing with PET-reinforced collagen. Mechanical tests showed the fabricated structure showed no significant differences with rat femoral bone with similar compressive strength of $62.1 \mathrm{MPa}$ and $61.86 \mathrm{Mpa}$ respectively. Earlier 
cell adhesion occurred in CNT scaffolds than PET-reinforced collagen scaffolds. CNTs block showed higher ALP activity with presence of recombinant human BMP-2, indicating good osteogenesis behavior. Tanaka et al. [189] further compared CNTs with hydroxyapatite (HA) in vitro and in vivo. Results showed that CNTs presented better protein absorption and release ability. In vivo tests showed that CNT porous structures had higher cell proliferation, better osteoconduction and more bone generated with the incorporation with recombinant human BMP-2. A variety of researches has already reported the combination of bioceramics such as hydroxyapatite and bioglass with CNTs for bone repair. Oyefusi et al. [190] grafted HA onto CNTs and graphene nanosheets and investigated these materials in terms of cell proliferation and differentiation by using human fetal osteoblastic cell line. Osteocalcin, an indicator of differentiation rate, was assessed by total protein assays and western blot analysis. Results showed that both CNTs-HA and grapheneHA materials supported cell growth and differentiation. Liu et al. [191] used CNTs as reinforcement fillers to enhance the mechanical properties of bioglass scaffolds including compressive strength (maximum value of $37.32 \mathrm{MPa}$ for samples containing $3 \mathrm{wt} \%$ of CNTs) and fracture toughness (maximum value of $1.58 \mathrm{MPa} \mathrm{m}^{1 / 2}$ for samples containing $3 w t \%$ of CNTs). Scaffolds were produced using a powderbed fusion additive manufacturing system. Cell studies using human osteosarcoma MG-63 cells showed the composite had good cytocompatibility. Khalid et al. [192] investigated MWCNT/HA scaffolds produced with different loadings of CNTs (1wt\%, 3wt \% and $5 \mathrm{wt} \%$ ). Results using human osteoblast sarcoma cell lines showed that the cytotoxicity of the composite scaffolds was dose-dependent and that cell viability decreased with the increase in CNT content.

Due to the brittleness and lack of flexibility of ceramic materials [193], CNTs have been combined with biocompatible and biodegradable polymers. Gupta et al. [194] fabricated polylactic-co-glycolic acid (PLAGA) and SWCNT composite microspheres for bone tissue engineering (Fig. 8a). MC3T3-E1 cells were studied in terms of adhesion, proliferation and gene expression. Results showed that MC3T3-E1 cells adhered, grew/survived and exhibited normal, non-stressed morphology and the addition of SWCNT strengthened cell proliferation rate and gene expression compared to pure PLAGA scaffolds. The authors further investigated the materials in vivo [195] and implanted composite materials into Sprague-Dawley rats for 2, 4,8 and 12 weeks of implantation time. Results showed that no mortality and clinical signs were observed. All groups were presenting continuously weight gain and the rate of gain for each group was similar. A slight toxicity was observed for PLAGA and SWCNT/PLAGA groups. The results seemed to indicate the in vivo biocompatibility of SWCNT/PLAGA composite. However, these results seemed no significant improvements were found in the bone tissue repair compared to the control group. This might be the absence of controlled porous structures allowing better cell communications and nutrients transform. Flores-Cedillo et al. [196] investigated MWCNTs/PCL composite films for bone tissue engineering. Three different scaffolds were fabricated including MWCNT/PCL with randomly dispersion, MWCNT/PCL

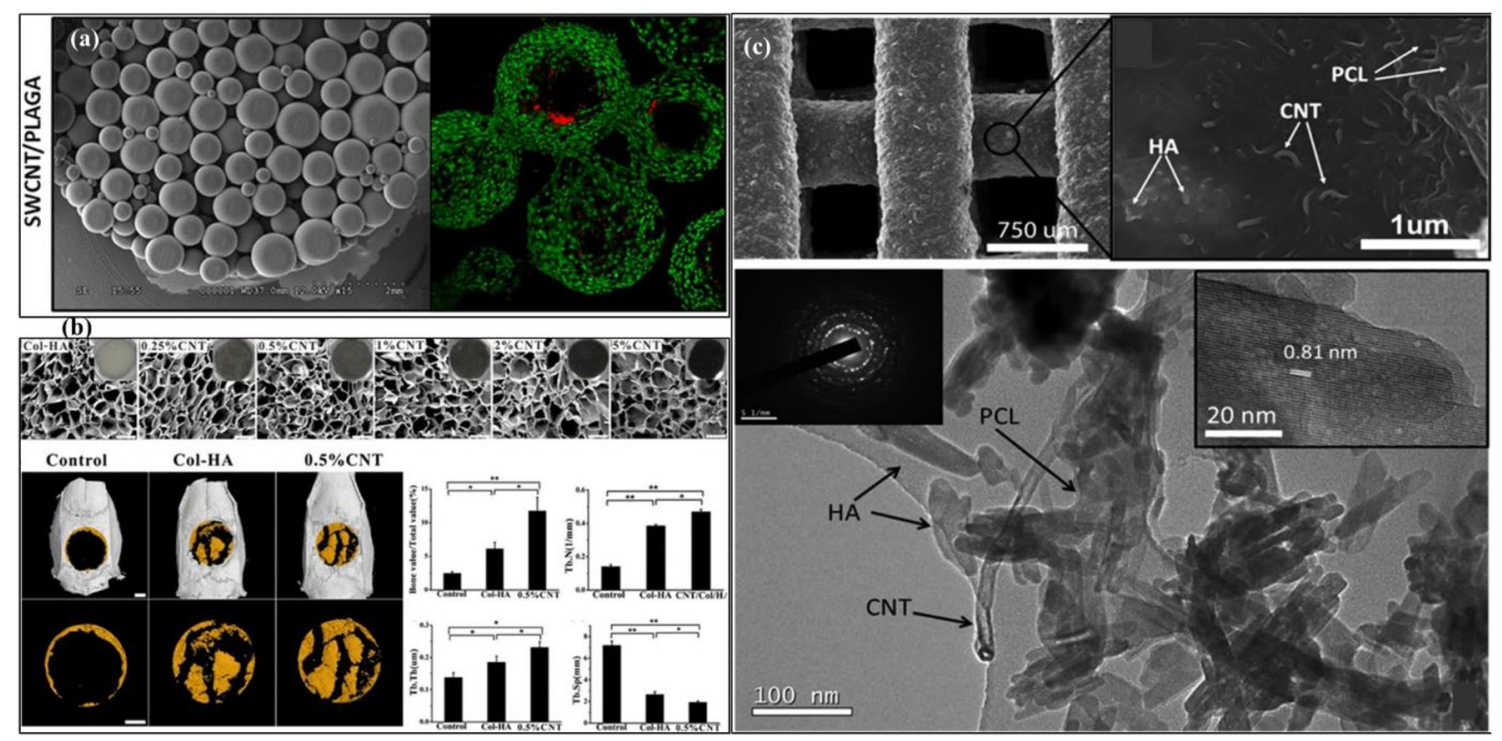

Fig. 8 a SEM images of SWCNT/PLAGA composite microspheres; fluorescence images showing cell survive at day $21 ; \mathbf{b} \mathrm{CNT} / \mathrm{Col} / \mathrm{HA}$ composite 2D membrane results including SEM images, micro-CT, mRNA expression and BSP and OCN protein expression; c SEM images showing morphology of 3D PCL/HA/MWCNT scaffold; TEM images illustrating interaction between HA and CNT (Refs. [99, 194, 195, 201, 202]) 
with aligned MWCNTs and $\beta$-glycerol phosphate (BGP) modified MWCNTs/PCL with aligned MWCNTs. Results showed that a comprehensive strengthen of physical properties including thermal, mechanical and electrical properties for CNT involved scaffolds. Cell seeding of human dental pulp stem cells (HDPSCs) showed that MWCNT and BGP on PCL showed higher proliferation rate as well as mineral depositions confirmed by Von Kossa and Alizarin red analysis. Similarly, Abdal-hay et al. [197] used air jet spinning to produce PCL/MWCNTs composite nanofibers with $0.5 \mathrm{wt} \%$ and $1 \mathrm{wt} \%$ loading of MWCNTs. Results showed $1 \mathrm{wt} \%$ PCL/MWCNTs presented a significant increase of tensile elastic modulus (650 MPa) and electrical conductivity $\left(83 \mu \mathrm{S} \cdot \mathrm{m}^{-1}\right)$. Cancian et al. [198] reported chitosanbased thermosensitive hydrogel scaffolds containing CNTs to improve poor mechanical and physiochemical properties, calcium deposition and ability of releasing protein drugs. Results showed that the addition of CNTs had a significant effect on sol-gel transition time and significantly increased compressive behaviour. In-vitro calcification studies showed that CNT had a major effect on the spatial arrangements of newly formed calcium deposits. Mesgar et al. [199] used freeze-dry techniques to produced gelatin-chitosan scaffolds loading different concentration of functionalized MWCNTs. An 11- and 9.6-fold increase in modulus were observed by adding MWCNTs but higher content of MWCNT led to a loss of mechanical property due to agglomeration. Immersion into stimulated body fluid showed the improved bonelike apatite layer formation with incorporation of CNTs. Shokri et al. [200] mixed bioglass, carbon nanotubes and gelatin and used a combination of hot press, salt leaching and cross-linked by Hexamethylenediisocyanate (HDI) to produced $\mathrm{Cs} / \mathrm{BG} / \mathrm{CNT}$ nanocomposite scaffold for bone tissue engineering. A variety of characterizations were taken to study mechanical property, biodegradability, and release of CNT after 30 days. Results showed that with addition of $4 \mathrm{wt} \%$ of CNT, the compressive strength reached up to $5.95 \pm 0.5 \mathrm{MPa}$. The water absorption was increased by adding CNTs and the amount of CNT released after 30 days was measured within $6 \times 10^{-4}$ and $1 \times 10^{-3} \mathrm{mg} / \mathrm{ml}$. Cell culture study of MG63 osteoblast showed no toxicity for this composite scaffolds.

Duan et al. [201] used a freeze drying method to create poly(L-lactic-acid)(PLLA)/CNTs scaffolds and their performance was investigated in vitro and in vivo. Scaffolds were seeded with bone marrow mesenchymal stem cells (BMSCs) and the in vitro results showed that the presence of CNTs enhanced cell proliferation, promoting also osteogenic differentiation. In vivo tests revealed that CNTs remarkably promoted the expression of osteogenesis-related proteins as well as the formation of collagen type I. Jing et al. [202] combined MWCNTs and collagen/hydroxyapatite to create $\mathrm{MWCNT} / \mathrm{Col} / \mathrm{HA}$ scaffolds using also a freeze-drying method. Results showed that MWCNT/Col/HA scaffold was tenfold stiffer than Col/HA scaffolds. In vitro analysis using BMSCs showed higher proliferation rate, mRNA and protein expressions of bone sialoprotein (BSP) and osteocalcin $(\mathrm{OCN})$ in scaffolds containing MWCNTs (Fig. 8b).

2D porous structure containing polymeric materials and CNTs were intensively reported. However, 3D porous structures involving CNTs are limited investigated. Goncalves et al. [99] reported 3D printed porous CNT scaffolds for bone tissue engineering (Fig. 8c). In this study, a pressureassisted extrusion-based additive manufacturing system was used to produce PCL-hydroxyapatite scaffolds filled with MWCNTs. A slurry was prepared by dissolving PCL pellets in dichloromethane. The MWCNT content varied between $0 \mathrm{wt} \%$ (i.e. $50 \mathrm{wt} \%$ of hydroxyapatite) and $10 \mathrm{wt} \%$ (i.e. 40 $\mathrm{wt} \%$ of hydroxyapatite) in a $50 \mathrm{wt} \%$ PCL matrix. Fully interconnected porous scaffolds were successfully produced with square pores in the range of 450-700 $\mu \mathrm{m}$. Preliminary cell proliferation testes (6 days) were conducted with MG63 osteoblast-like cells. Improved results were obtained with scaffolds containing $10 \mathrm{wt} \%$ of MWCNTs. Recently, Wang et al. [203] introduced a polymethyl methacrylate (PMMA) bone cement incorporated with different loads of MWCNTs $(0.1,0.25,0.5$ and $1 \mathrm{wt} \%)$ using the injection moulding for the high-load joint replacement. The in-vitro results demonstrated promoted rat bone marrow mesenchymal stem cell (rBMSCs) adhesion and proliferation. The osteogenic differentiation was also increased from both gene and protein expression levels. In-vivo tests indicated that $1 \mathrm{wt} \%$ loading of MWCNTs into PMMA bone cement significantly enhance bone ingrowth with ingrowth ratio up to $42 \%$ after 12 weeks post-surgery.

Swietek et al. [204] reported PCL based 3D composite scaffolds incorporated with functionalized CNTs (fCNTs) and iron oxide (ION) with two different mass ratios (1:1 and 1:4) using the solvent casting method for bone tissue regeneration. The hydroxylated CNTs were firstly mixed with IONs to prepare hybrid nanoparticles, then mixed with PCL matrix and eventually fabricated into 3D composite scaffolds by the solvent casting/porogen leaching. The SAOS-2 human cell line was used to assess the cytotoxicity. Results showed that the presence of fCNTs up to $1 \mathrm{wt} \%$ improved the cell attachment and a concentration of IONs below $1 \mathrm{wt} \%$ increased the cell metabolic activity, indicating the composite scaffolds are potential candidate's materials for bone tissue regeneration.

\section{Limitations and future prospective}

Although CNTs are becoming attractive nanomaterials, acting as reinforce fillers incorporating with biocompatible polymeric materials and widely used in the nerve, cardiac and bone tissue engineering, several major limitations still 
remain and further developments are still required to deeply promote the translation of CNTs into tissue engineering applications and secure the long-term clinical success.

The strategies to develop non-toxicity, safe and green CNTs and their polymeric composite still remain a significant challenge in the field of regenerative tissue engineering. The toxicity of CNTs is still an open issue. Although the physiochemical properties (such as mechanical strength and electrical conductivity) and biological properties (such as cell proliferation and differentiation) are promoted accordingly by increasing the concentration of CNTs in the polymeric composite, researchers usually tend to use smaller amount of the CNTs in the polymeric composite (mostly below $10 \mathrm{wt} \%$ ) in order to minimize the potential toxicity effects. However, the reduction of CNTs in the polymeric composite might inhibit the mechanical, electrical and biological properties of CNTs composite. Therefore, this put forwards higher requirements for the fabrication of safer and greener CNTs in the future tissue engineering applications. This can be achieved by optimizing and improving CNTs fabrication process to acutely produce CNTs with proper diameter, length and structure which will not induce toxicity in cellular level. Safer, greener and more efficient catalysts are also required to minimize the residual toxic effects due to the oxidative stress and anti-oxidant depletion. Meanwhile, the investigations of mechanisms how CNTs induce toxicity are still required to further exploit the potential factors which will cause the cytotoxicity and genotoxicity. Most research studies focus on the in vitro early stages of cell culture, the long-term in vivo studies must be considered, including the degradation of polymeric materials, leading to the release of CNTs. It will be a significant consideration for researchers in future to develop well strategies to balance the toxicity effects and varies characteristics when they design CNTs/ polymeric composites.

Another factor hindering the use of high content of CNTs is the processing technology. Due to the unique hydrophobic surface nature and strong Van de Waals forces, CNTs are insoluble in water and most organic solvents and easily agglomerated. This makes CNTs difficult to homogenously disperse in the polymeric matrix, especially in the molten state polymer. High content of CNTs further strengthen this agglomeration and have a significant impact on the rheological behavior. High loading of MWCNTs in the molten-state polymer matrix lead to the phase transition shifting from "liquid-like" to "solid-like" rheological behavior and high content of MWCNTs easily causes agglomeration, leading to the nozzle clogging [125]. There is an unmet need to improve the CNTs processing technology. The use of surfactant or the modification of CNT surface might provide a promising approach allowing more intimate interactions between CNT surfaces and polymer chains. Jakus et al. [205] reported using the mixture of dichloromethane (DCM), 2-butoxyethanol and dibutyl phthalate in a ratio of 10:2:1 by mass to produce high loading of graphene ink in the polylactide-co-glycolide (PLG) solution (up to $75 \mathrm{wt} \%$ ) and successfully using the extrusion 3D printing technique to fabricate 3D porous scaffolds for the human cadaver nerve model. Xiong et al. [206] investigated a thiol grafting method in functionalizing MWCNT surfaces to develop MWNTthiol-acrylate composite resin for two-photon polymerization (TPP) process and the composite resin had high concentration MWCNTs up to $0.2 \mathrm{wt} \%$, significantly improving the electrical and mechanical properties of 3D micro/nanostructures. In addition, optimizing the preparation process might be also helpful, such as the increase of sonication time contributing to increasing the concentration of graphene in the solvent [207]. As mentioned in the previous section, in situ polymerization is also a viable option to produce homogeneous dispersion of CNTs in the polymer matrix and might increase the content of CNTs. However, it has to be specifically noted in terms of their printability or the rheological change when applied high content of CNTs. The use of branched CNTs might address this issue by lowering the rheological threshold as mentioned in previous section.

Recently, there is a growing trend to utilize polymer based composite containing CNTs to produce 3D scaffolds for nerve, cardiac and bone tissue engineering. Comparing to $2 \mathrm{D}$ membrane or meshes, 3D printed scaffolds are more suitable to mimic the 3D environment of native tissues. The unique fabrication processes allow more complex internal/ external structures of scaffolds, ranging from nano-scale to marcro-scale levels. These characteristics are specifically attractive to produce multiple scales human tissues from marcro organs to nano vascular networks. However, how to prepare polymer/CNTs solution or composite which are able to print still remain a challenge to address for the future CNTs usage in the tissue engineering domains. Moreover, comparing to the $2 \mathrm{D}$ membrane/meshes which have more compact structures, allowing more intimate polymers-CNTs and cells-materials interactions, 3D printed scaffolds, due to their smaller specific surface area, might suffer from decreased characteristics such as electrical conductivities and biological properties at the same concentrations of CNTs in 2D membranes and meshes. Therefore, further developments are expected in future to produce 3D scaffolds with higher concentration of CNTs, more organized spatial arrangements (alignments of CNTs), and more intimate interactions between CNTs and polymer matrix. In future, with the development of different additive manufacturing systems, more hierarchical and multi-material scaffolds closely replicating the natural environment for cell proliferation and differentiation will be developed. Incorporating with electrical stimulation, CNTs and their polymeric 
composite will greatly put forward the development of tissue engineering.

\section{Conclusions}

CNTs, with exceptional physical properties including mechanical, thermal, and electrical properties, have been widely used in electronic applications, energy storage and photovoltaics, and more recently for medical applications. To improve the dispersity in aqueous media and minimise the toxicity, CNTs are usually functionalized with different functional groups (such as $-\mathrm{OH}$ and $-\mathrm{COOH}$ ) by the covalent and non-covalent approaches. Nevertheless, the toxicity of CNTs is still an open issue with several papers showing opposite trends. However, as discussed in this review paper, potential toxic effects of CNTs are mainly derived from the cellular internalization of CNTs and oxidative stresses, which might be resulted from a variety of aspects including dimensions, shape, dose, synthesis process, and surface characteristics and so on. The processing of polymeric composites containing CNTs are strongly depended on the desired properties, chemical compositions, ease of synthesis of composite and cost considerations and it has to trade off some properties for a specific case. The rheological behaviour of composite is a significant consideration for successfully producing CNTs involved constructs. In the field of tissue engineering, CNTs have been mainly used as a reinforcement filler in the polymer-based scaffolds, improving mechanical and electrical properties and allowing the fabrication of scaffolds for neural, cardiac and bone tissue engineering. The addition of CNTs in the polymer matrix can promote the conductivity of the nerve related scaffold and enhance the nerve cell responses. It also promotes the conductivity, elastic strength and biological responses of the cardiac related scaffolds. For bone tissue engineering, CNTs are used to reinforce the mechanical properties and the biological properties. In the future, non-toxicity, safer and greener CNTs and their polymeric composite are still expected and the investigations of mechanisms how CNTs induce toxicity are still required to further exploit the potential factors which will cause the cytotoxicity and genotoxicity. Most research studies focus on the in vitro early stages of cell culture, so long-term in vivo studies must be considered, including the degradation of polymeric materials, leading to the release of CNTs. Current studies investigate the low content of CNTs in the scaffolds due to the fabrication limitations and toxicity while it trades off the scaffolds properties such as electrical, mechanical and biological properties. Thus, higher concentrations of CNTs in the polymer matrix are expected. In order to mimic the 3D environment of biological tissues, additive manufacturing (e.g. extrusion-based processes and vat-photopolymerization) has been used to create scaffolds with controlled architecture showing improved characteristics compared to $2 \mathrm{D}$ membranes or electrospun meshes. In the future, different additive manufacturing systems will be used to create hierarchical and multi-material scaffolds closely replicating the natural environment for cell proliferation and differentiation and eventually translate CNTs involved polymer composite scaffolds into the clinical success.

Acknowledgements The author wishes to acknowledge the research grant funded by the University of Manchester/King Saud University "Multi scale bioactive scaffolds for bone regeneration" project.

\section{Compliance with ethical standards}

Conflict of interest There is no conflict of interest.

Open Access This article is licensed under a Creative Commons Attribution 4.0 International License, which permits use, sharing, adaptation, distribution and reproduction in any medium or format, as long as you give appropriate credit to the original author(s) and the source, provide a link to the Creative Commons licence, and indicate if changes were made. The images or other third party material in this article are included in the article's Creative Commons licence, unless indicated otherwise in a credit line to the material. If material is not included in the article's Creative Commons licence and your intended use is not permitted by statutory regulation or exceeds the permitted use, you will need to obtain permission directly from the copyright holder. To view a copy of this licence, visit http://creativecommons.org/licenses/by/4.0/.

\section{References}

1. Harrison BS, Atala A (2007) Carbon nanotube applications for tissue engineering. Biomaterials 28(2):344-353

2. Pati F, Gantelius J, Svahn HA (2016) 3D bioprinting of tissue/ organ models. Angew Chem Int Ed 55(15):4650-4665

3. Bártolo P, Chua C, Almeida H, Chou S, Lim A (2009) Biomanufacturing for tissue engineering: present and future trends. Virtual Phys Prototyp 4(4):203-216

4. Iijima S (1991) Helical microtubules of graphitic carbon. Nature 354:56

5. Kharitonov A, Tkachev A, Blohin A, Dyachkova T, Kobzev D, Maksimkin A, Mostovoy A, Alekseiko L (2016) Reinforcement of Bisphenol-F epoxy resin composites with fluorinated carbon nanotubes. Compos Sci Technol 134:161-167

6. Bhatia R, Ujjain SK (2017) Soluble single-walled carbon nanotubes for photovoltaics. Mater Lett 190:165-168

7. Wang C, Feng Y, Sun X, Sun H, Peng T, Lu Y, Xu J, Luo Y, Yu B (2017) Fabrication and activation of carbon nanotube foam and its application in energy storage. Electrochim Acta 236:343-350

8. Amenta V, Aschberger K (2015) Carbon nanotubes: potential medical applications and safety concerns. Wiley Interdiscip Rev Nanomed Nanobiotechnol 7(3):371-386

9. Ali MA, Solanki PR, Srivastava S, Singh S, Agrawal VV, John R, Malhotra BD (2015) Protein functionalized carbon nanotubes-based smart lab-on-a-chip. ACS Appl Mater Interfaces 7(10):5837-5846

10. Caoduro C, Hervouet E, Girard-Thernier C, Gharbi T, Boulahdour H, Delage-Mourroux R, Pudlo M (2017) Carbon nanotubes 
as gene carriers: focus on internalization pathways related to functionalization and properties. Acta Biomater 49:36-44

11. Sajid MI, Jamshaid U, Jamshaid T, Zafar N, Fessi H, Elaissari A (2016) Carbon nanotubes from synthesis to in vivo biomedical applications. Int J Pharm 501(1-2):278-299

12. Zhou M, Lozano N, Wychowaniec JK, Hodgkinson T, Richardson SM, Kostarelos K, Hoyland JA (2019) Graphene oxide: a growth factor delivery carrier to enhance chondrogenic differentiation of human mesenchymal stem cells in 3D hydrogels. Acta Biomater 96:271-280

13. Hopley EL, Salmasi S, Kalaskar DM, Seifalian AM (2014) Carbon nanotubes leading the way forward in new generation 3D tissue engineering. Biotechnol Adv 32(5):1000-1014

14. Gajendiran M, Choi J, Kim S-J, Kim K, Shin H, Koo H-J, Kim K (2017) Conductive biomaterials for tissue engineering applications. J Ind Eng Chem. https://doi.org/10.1016/j. jiec.2017.02.031

15. Ku SH, Lee M, Park CB (2013) Carbon-based nanomaterials for tissue engineering. Adv Healthc Mater 2(2):244-260

16. Balasubramanian K, Burghard M (2005) Chemically functionalized carbon nanotubes. Small 1(2):180-192

17. He H, Pham-Huy LA, Dramou P, Xiao D, Zuo P, Pham-Huy C (2013) Carbon nanotubes: applications in pharmacy and medicine. BioMed Res Int. https://doi.org/10.1155/2013/578290

18. Iijima S, Brabec C, Maiti A, Bernholc J (1996) Structural flexibility of carbon nanotubes. J Chem Phys 104(5):2089-2092

19. Demczyk B, Wang Y, Cumings J, Hetman M, Han W, Zettl A, Ritchie R (2002) Direct mechanical measurement of the tensile strength and elastic modulus of multiwalled carbon nanotubes. Mater Sci Eng, A 334(1-2):173-178

20. Yu M-F, Files BS, Arepalli S, Ruoff RS (2000) Tensile loading of ropes of single wall carbon nanotubes and their mechanical properties. Phys Rev Lett 84(24):5552

21. Thostenson ET, Ren Z, Chou T-W (2001) Advances in the science and technology of carbon nanotubes and their composites: a review. Compos Sci Technol 61(13):1899-1912

22. Falvo MR, Clary G, Taylor Ii R, Chi V, Brooks F Jr, Washburn RS (1997) Superfine, Bending and buckling of carbon nanotubes under large strain. Nature 389(6651):582

23. Nardecchia S, Carriazo D, Ferrer ML, Gutiérrez MC, del Monte F (2013) Three dimensional macroporous architectures and aerogels built of carbon nanotubes and/or graphene: synthesis and applications. Chem Soc Rev 42(2):794-830

24. Orlita M, Faugeras C, Plochocka P, Neugebauer P, Martinez G, Maude DK, Barra A-L, Sprinkle M, Berger C, De Heer WA (2008) Approaching the Dirac point in high-mobility multilayer epitaxial graphene. Phys Rev Lett 101(26):267601

25. Dresselhaus MS, Avouris P (2001) Introduction to carbon materials research. Carbon nanotubes. Springer, Berlin, pp 1-9

26. Avouris P, Appenzeller J, Martel R, Wind SJ (2003) Carbon nanotube electronics. Proc IEEE 91(11):1772-1784

27. Newman P, Minett A, Ellis-Behnke R, Zreiqat H (2013) Carbon nanotubes: their potential and pitfalls for bone tissue regeneration and engineering. Nanomed Nanotechnol Biol Med 9(8):1139-1158

28. Meng L, Fu C, Lu Q (2009) Advanced technology for functionalization of carbon nanotubes. Prog Nat Sci 19(7):801-810

29. Merum S, Veluru JB, Seeram R (2017) Functionalized carbon nanotubes in bio-world: applications, limitations and future directions. Mater Sci Eng, B 223:43-63

30. Gupta S, Murthy C, Prabha CR (2017) Recent advances in carbon nanotube based electrochemical biosensors. Int J Biol Macromol. https://doi.org/10.1016/j.ijbiomac.2017.12.038

31. Oliveira SF, Bisker G, Bakh NA, Gibbs SL, Landry MP, Strano MS (2015) Protein functionalized carbon nanomaterials for biomedical applications. Carbon 95:767-779
32. Ajayan PM, Tour JM (2007) Materials science: nanotube composites. Nature 447(7148): 1066

33. Kaur P, Shin M-S, Park J-S, Verma G, Sekhon SS (2018) Supramolecular modification of carbon nanofibers with poly (diallyl dimethylammonium) chloride and Triton X-100 for electrochemical application. Int J Hydrog Energy 43(13):6575-6585

34. Behnam B, Shier WT, Nia AH, Abnous K, Ramezani M (2013) Non-covalent functionalization of single-walled carbon nanotubes with modified polyethyleneimines for efficient gene delivery. Int J Pharm 454(1):204-215

35. Pantarotto D, Singh R, McCarthy D, Erhardt M, Briand JP, Prato M, Kostarelos K, Bianco A (2004) Functionalized carbon nanotubes for plasmid DNA gene delivery. Angew Chem 116(39):5354-5358

36. Singh R, Pantarotto D, McCarthy D, Chaloin O, Hoebeke J, Partidos CD, Briand J-P, Prato M, Bianco A, Kostarelos K (2005) Binding and condensation of plasmid DNA onto functionalized carbon nanotubes: toward the construction of nanotube-based gene delivery vectors. J Am Chem Soc 127(12):4388-4396

37. Zhang Y, Bai Y, Yan B (2010) Functionalized carbon nanotubes for potential medicinal applications. Drug Discov Today 15(11-12):428-435

38. Barzegar A, Mansouri A, Azamat J (2016) Molecular dynamics simulation of non-covalent single-walled carbon nanotube functionalization with surfactant peptides. J Mol Graph Model 64:75-84

39. Kim W-J, Nair N, Lee CY, Strano MS (2008) Covalent functionalization of single-walled carbon nanotubes alters their densities allowing electronic and other types of separation. J Phys Chem C 112(19):7326-7331

40. Zhu W, Minami N, Kazaoui S, Kim Y (2003) Fluorescent chromophore functionalized single-wall carbon nanotubes with minimal alteration to their characteristic one-dimensional electronic states. J Mater Chem 13(9):2196-2201

41. You Y-Z, Hong C-Y, Pan C-Y (2006) Directly growing ionic polymers on multi-walled carbon nanotubes via surface RAFT polymerization. Nanotechnology 17(9):2350

42. Prabhavathi G, Yamuna R, Jafer AC (2018) Covalent functionalization and solubilization of multi-walled carbon nanotubes by using zinc and copper complexes of meso-tetra (4-aminophenyl) porphyrin. J Organomet Chem 861:219-229

43. Redondo-Gómez C, Orozco F, Noeske P-LM, Soto-Tellini V, Corrales-Urena Y, Vega-Baudrit J (2017) Cholic acid covalently bound to multi-walled carbon nanotubes: Improvements on dispersion stability. Mater Chem Phys 200:331-341

44. Nosek M, Sainio J, Joensuu PM (2018) 2, 2'-bipyridine-functionalized single-walled carbon nanotubes: the formation of transition metal complexes and their charge transfer effects. Carbon 129:175-182

45. Costa PM, Bourgognon M, Wang JT, Al-Jamal KT (2016) Functionalised carbon nanotubes: from intracellular uptake and cellrelated toxicity to systemic brain delivery. J Control Release 241:200-219

46. Shi Kam NW, Jessop TC, Wender PA, Dai H (2004) Nanotube molecular transporters: internalization of carbon nanotubeprotein conjugates into mammalian cells. J Am Chem Soc 126(22):6850-6851

47. Cui X, Wan B, Yang Y, Ren X, Guo L-H (2017) Length effects on the dynamic process of cellular uptake and exocytosis of singlewalled carbon nanotubes in murine macrophage cells. Sci Rep 7(1): 1518

48. Lacerda L, Ali-Boucetta H, Herrero MA, Pastorin G, Bianco A, Prato M, Kostarelos K (2008) Tissue histology and physiology following intravenous administration of different types of 
functionalized multiwalled carbon nanotubes. Nanomedicine. https://doi.org/10.2217/17435889.3.2.149

49. Petros RA, DeSimone JM (2010) Strategies in the design of nanoparticles for therapeutic applications. Nat Rev Drug Discov 9(8):615

50. Kam NWS, Dai H (2005) Carbon nanotubes as intracellular protein transporters: generality and biological functionality. J Am Chem Soc 127(16):6021-6026

51. Shi X, von Dem Bussche A, Hurt RH, Kane AB, Gao H (2011) Cell entry of one-dimensional nanomaterials occurs by tip recognition and rotation. Nat Nanotechnol 6(11):714

52. Pantarotto D, Briand J-P, Prato M, Bianco A (2004) Translocation of bioactive peptides across cell membranes by carbon nanotubes. Chem Commun. https://doi.org/10.1039/b311254c

53. Lacerda L, Ali-Boucetta H, Kraszewski S, Tarek M, Prato M, Ramseyer C, Kostarelos K, Bianco A (2013) How do functionalized carbon nanotubes land on, bind to and pierce through model and plasma membranes. Nanoscale 5(21):10242-10250

54. Kraszewski S, Bianco A, Tarek M, Ramseyer C (2012) Insertion of short amino-functionalized single-walled carbon nanotubes into phospholipid bilayer occurs by passive diffusion. PLOS ONE 7(7):e40703

55. Lacerda L, Russier J, Pastorin G, Herrero MA, Venturelli E, Dumortier H, Al-Jamal KT, Prato M, Kostarelos K, Bianco A (2012) Translocation mechanisms of chemically functionalised carbon nanotubes across plasma membranes. Biomaterials 33(11):3334-3343

56. Mu Q, Broughton DL, Yan B (2009) Endosomal leakage and nuclear translocation of multiwalled carbon nanotubes: developing a model for cell uptake. Nano Lett 9(12):4370-4375

57. Bussy C, Ali-Boucetta H, Kostarelos K (2012) Safety considerations for graphene: lessons learnt from carbon nanotubes. Acc Chem Res 46(3):692-701

58. Neves V, Heister E, Costa S, Tîlmaciu C, Borowiak-Palen E, Giusca CE, Flahaut E, Soula B, Coley HM, McFadden J (2010) Uptake and release of double-walled carbon nanotubes by mammalian cells. Adv Func Mater 20(19):3272-3279

59. Mao H, Kawazoe N, Chen G (2013) Uptake and intracellular distribution of collagen-functionalized single-walled carbon nanotubes. Biomaterials 34(10):2472-2479

60. Marangon I, Boggetto N, Ménard-Moyon CC, Venturelli E, Béoutis M-L, Péchoux C, Luciani N, Wilhelm C, Bianco A, Gazeau F (2012) Intercellular carbon nanotube translocation assessed by flow cytometry imaging. Nano lett 12(9):4830-4837

61. Orecna M, De Paoli SH, Janouskova O, Tegegn TZ, Filipova M, Bonevich JE, Holada K, Simak J (2014) Toxicity of carboxylated carbon nanotubes in endothelial cells is attenuated by stimulation of the autophagic flux with the release of nanomaterial in autophagic vesicles. Nanomed Nanotechnol Biol Med 10(5):e939-e948

62. Sato Y, Yokoyama A, Nodasaka Y, Kohgo T, Motomiya K, Matsumoto H, Nakazawa E, Numata T, Zhang M, Yudasaka M (2013) Long-term biopersistence of tangled oxidized carbon nanotubes inside and outside macrophages in rat subcutaneous tissue. Sci Rep 3:2516

63. Goode AE, Carter DAG, Motskin M, Pienaar IS, Chen S, Hu S, Ruenraroengsak P, Ryan MP, Shaffer MS, Dexter DT (2015) High resolution and dynamic imaging of biopersistence and bioreactivity of extra and intracellular MWNTs exposed to microglial cells. Biomaterials 70:57-70

64. Lanone S, Andujar P, Kermanizadeh A, Boczkowski J (2013) Determinants of carbon nanotube toxicity. Adv Drug Deliv Rev 65(15):2063-2069

65. Murphy FA, Poland CA, Duffin R, Donaldson K (2012) Lengthdependent pleural inflammation and parietal pleural responses after deposition of carbon nanotubes in the pulmonary airspaces of mice. Nanotoxicology 7(6):1157-1167

66. Xu J, Alexander DB, Futakuchi M, Numano T, Fukamachi K, Suzui M, Omori T, Kanno J, Hirose A, Tsuda H (2014) Size-and shape-dependent pleural translocation, deposition, fibrogenesis, and mesothelial proliferation by multiwalled carbon nanotubes. Cancer Sci 105(7):763-769

67. Boyles MS, Young L, Brown DM, MacCalman L, Cowie H, Moisala A, Smail F, Smith PJ, Proudfoot L, Windle AH (2015) Multi-walled carbon nanotube induced frustrated phagocytosis, cytotoxicity and pro-inflammatory conditions in macrophages are length dependent and greater than that of asbestos. Toxicol In Vitro 29(7):1513-1528

68. Zhang M, Yang M, Morimoto T, Tajima N, Ichiraku K, Fujita K, Iijima S, Yudasaka M, Okazaki T (2018) Size-dependent cell uptake of carbon nanotubes by macrophages: a comparative and quantitative study. Carbon 127:93-101

69. Journet C, Maser W, Bernier P, Loiseau A, de La Chapelle ML, Lefrant DS, Deniard P, Lee R, Fischer J (1997) Large-scale production of single-walled carbon nanotubes by the electric-arc technique. Nature 388(6644):756

70. Thess A, Lee R, Nikolaev P, Dai H, Petit P, Robert J, Xu C, Lee YH, Kim SG, Rinzler AG (1996) Crystalline ropes of metallic carbon nanotubes. Science 273(5274):483-487

71. Cassell AM, Raymakers JA, Kong J, Dai H (1999) Large scale CVD synthesis of single-walled carbon nanotubes. J Phys Chem B 103(31):6484-6492

72. Xiao L, Chen Z, Feng C, Liu L, Bai Z-Q, Wang Y, Qian L, Zhang Y, Li Q, Jiang K (2008) Flexible, stretchable, transparent carbon nanotube thin film loudspeakers. Nano Lett 8(12):4539-4545

73. Endo M, Hayashi T, Kim Y-A (2006) Large-scale production of carbon nanotubes and their applications. Pure Appl Chem 78(9):1703-1713

74. Visalli G, Facciolà A, Iannazzo D, Piperno A, Pistone A, Di Pietro A (2017) The role of the iron catalyst in the toxicity of multi-walled carbon nanotubes (MWCNTs). J Trace Elem Med Biol 43:153-160

75. Kagan V, Tyurina Y, Tyurin V, Konduru N, Potapovich A, Osipov A, Kisin E, Schwegler-Berry D, Mercer R, Castranova V (2006) Direct and indirect effects of single walled carbon nanotubes on RAW 264.7 macrophages: role of iron. Toxicol Lett 165(1):88-100

76. Pulskamp K, Diabaté S, Krug HF (2007) Carbon nanotubes show no sign of acute toxicity but induce intracellular reactive oxygen species in dependence on contaminants. Toxicol Lett 168(1):58-74

77. Shvedova A, Castranova V, Kisin E, Schwegler-Berry D, Murray A, Gandelsman V, Maynard A, Baron P (2003) Exposure to carbon nanotube material: assessment of nanotube cytotoxicity using human keratinocyte cells. J Toxicol Environ Health Part A 66(20):1909-1926

78. Hou P, Bai S, Yang Q, Liu C, Cheng H (2002) Multi-step purification of carbon nanotubes. Carbon 40(1):81-85

79. Muller J, Huaux F, Fonseca A, Nagy JB, Moreau N, Delos M, Raymundo-Piñero E, Béguin F, Kirsch-Volders M, Fenoglio I (2008) Structural defects play a major role in the acute lung toxicity of multiwall carbon nanotubes: toxicological aspects. Chem Res Toxicol 21(9):1698-1705

80. Fenoglio I, Greco G, Tomatis M, Muller J, Raymundo-Pinero E, Béguin F, Fonseca A, Nagy JB, Lison D, Fubini B (2008) Structural defects play a major role in the acute lung toxicity of multiwall carbon nanotubes: physicochemical aspects. Chem Res Toxicol 21(9):1690-1697

81. Jiang W, Wang Q, Qu X, Wang L, Wei X, Zhu D, Yang K (2017) Effects of charge and surface defects of multi-walled carbon 
nanotubes on the disruption of model cell membranes. Sci Total Environ 574:771-780

82. Liu Z, Dong X, Song L, Zhang H, Liu L, Zhu D, Song C, Leng X (2014) Carboxylation of multiwalled carbon nanotube enhanced its biocompatibility with L02 cells through decreased activation of mitochondrial apoptotic pathway. J Biomed Mater Res, Part A 102(3):665-673

83. Jain S, Thakare VS, Das M, Godugu C, Jain AK, Mathur R, Chuttani K, Mishra AK (2011) Toxicity of multiwalled carbon nanotubes with end defects critically depends on their functionalization density. Chem Res Toxicol 24(11):2028-2039

84. Sager TM, Wolfarth MW, Andrew M, Hubbs A, Friend S, Chen T-H, Porter DW, Wu N, Yang F, Hamilton RF (2014) Effect of multi-walled carbon nanotube surface modification on bioactivity in the C57BL/6 mouse model. Nanotoxicology 8(3):317-327

85. Allegri M, Perivoliotis DK, Bianchi MG, Chiu M, Pagliaro A, Koklioti MA, Trompeta A-FA, Bergamaschi E, Bussolati O, Charitidis CA (2016) Toxicity determinants of multi-walled carbon nanotubes: the relationship between functionalization and agglomeration. Toxicol Rep 3:230-243

86. Shvedova AA, Pietroiusti A, Fadeel B, Kagan VE (2012) Mechanisms of carbon nanotube-induced toxicity: focus on oxidative stress. Toxicol Appl Pharmacol 261(2):121-133

87. Zhang T, Tang M, Kong L, Li H, Zhang T, Xue Y, Pu Y (2015) Surface modification of multiwall carbon nanotubes determines the pro-inflammatory outcome in macrophage. J Hazard Mater 284:73-82

88. Lucia UC, Delia C, Aureliano C, Maria FA, Raffaele M, Buresti G, Casciardi S, Iavicoli S (2015) Cytotoxic, genotoxic and proinflammatory response of human bronchial cells to pristine and functionalized MWCNTs. Mater Today Proc 2(1):126-133

89. Zhou L, Forman HJ, Ge Y, Lunec J (2017) Multi-walled carbon nanotubes: a cytotoxicity study in relation to functionalization, dose and dispersion. Toxicol In Vitro 42:292-298

90. Walkey CD, Chan WC (2012) Understanding and controlling the interaction of nanomaterials with proteins in a physiological environment. Chem Soc Rev 41(7):2780-2799

91. Ge C, Du J, Zhao L, Wang L, Liu Y, Li D, Yang Y, Zhou R, Zhao Y, Chai Z (2011) Binding of blood proteins to carbon nanotubes reduces cytotoxicity. Proc Natl Acad Sci 108(41):16968-16973

92. Lu N, Sui Y, Ding Y, Tian R, Li L, Liu F (2018) Adsorption of human serum albumin on functionalized single-walled carbon nanotubes reduced cytotoxicity. Chem Biol Interact. https://doi. org/10.1016/j.cbi.2018.03.015

93. Shannahan JH, Brown JM, Chen R, Ke PC, Lai X, Mitra S, Witzmann FA (2013) Comparison of nanotube-protein corona composition in cell culture media. Small 9(12):2171-2181

94. Podila R, Vedantam P, Ke P, Brown J, Rao AM (2012) Evidence for charge-transfer-induced conformational changes in carbon nanostructure-protein corona. J Phys Chem C 116(41):22098-22103

95. Zhao X, Lu D, Hao F, Liu R (2015) Exploring the diameter and surface dependent conformational changes in carbon nanotubeprotein corona and the related cytotoxicity. J Hazard Mater 292:98-107

96. Khan W, Sharma R, Saini P (2016) Carbon nanotube-based polymer composites: synthesis, properties and applications. Carbon Nanotubes-Curr Prog Polym Compos. https://doi. org/10.5772/62497

97. Li H, Minus ML (2017) On the formation of potential polymernanotube blends by liquid-solid phase separation. Polymer 131:179-192

98. Serrano MC, Gutiérrez MC, del Monte F (2014) Role of polymers in the design of 3D carbon nanotube-based scaffolds for biomedical applications. Prog Polym Sci 39(7):1448-1471
99. Gonçalves EM, Oliveira FJ, Silva RF, Neto MA, Fernandes MH, Amaral M, Vallet-Regí M, Vila M (2016) Three-dimensional printed PCL-hydroxyapatite scaffolds filled with CNTs for bone cell growth stimulation. J Biomed Mater Res B Appl Biomater 104(6):1210-1219

100. Wang Z, Crandall C, Sahadevan R, Menkhaus TJ, Fong H (2017) Microfiltration performance of electrospun nanofiber membranes with varied fiber diameters and different membrane porosities and thicknesses. Polymer 114:64-72

101. Ding J, Zhang J, Li J, Li D, Xiao C, Xiao H, Yang H, Zhuang X, Chen X (2019) Electrospun polymer biomaterials. Prog Polym Sci 90:1-34

102. Li D, Wang Y, Xia Y (2004) Electrospinning nanofibers as uniaxially aligned arrays and layer-by-layer stacked films. Adv Mater 16(4):361-366

103. Liu W, Zhang X, Xu G, Bradford PD, Wang X, Zhao H, Zhang Y, Jia Q, Yuan F-G, Li Q, Qiu Y, Zhu Y (2011) Producing superior composites by winding carbon nanotubes onto a mandrel under a poly(vinyl alcohol) spray. Carbon 49(14):4786-4791

104. Gupta P, Rajput M, Singla N, Kumar V, Lahiri D (2016) Electric field and current assisted alignment of CNT inside polymer matrix and its effects on electrical and mechanical properties. Polymer 89:119-127

105. Kharaziha M, Shin SR, Nikkhah M, Topkaya SN, Masoumi N, Annabi N, Dokmeci MR, Khademhosseini A (2014) Tough and flexible CNT-polymeric hybrid scaffolds for engineering cardiac constructs. Biomaterials 35(26):7346-7354

106. Scotti KL, Dunand DC (2018) Freeze casting - a review of processing, microstructure and properties via the open data repository, FreezeCasting.net. Prog Mater Sci 94:243-305

107. Mitchell GR, Tojeira A (2013) Role of anisotropy in tissue engineering. Procedia Eng 59:117-125

108. Ghalia MA, Dahman Y (2016) Advanced nanobiomaterials in tissue engineering: Synthesis, properties, and applications (chapter 6). In: Grumezescu AM (ed) Nanobiomaterials in soft tissue engineering. William Andrew Publishing, Norwich, pp 141-172

109. Gomes ME, Reis RL (2004) Biodegradable polymers and composites in biomedical applications: from catgut to tissue engineering. Part 2 Systems for temporary replacement and advanced tissue regeneration. Int Mater Rev 49(5):274-285

110. Ho CMB, Mishra A, Lin PTP, Ng SH, Yeong WY, Kim Y-J, Yoon Y-J (2017) 3D printed polycaprolactone carbon nanotube composite scaffolds for cardiac tissue engineering. Macromol Biosci 17(4):1600250

111. Paszkiewicz S, Szymczyk A (2019) Graphene-based nanomaterials and their polymer nanocomposites (chapter 6). In: Karak $\mathrm{N}$ (ed) Nanomaterials and polymer nanocomposites. Elsevier, Amsterdam, pp 177-216

112. Tang L-C, Zhao L, Qiang F, Wu Q, Gong L-X, Peng J-P (2019) Chapter Twelve: mechanical properties of rubber nanocomposites containing carbon nanofillers. In: Yaragalla S, Mishra RK, Thomas S, Kalarikkal N, Maria HJ (eds) Carbon-based nanofillers and their rubber nanocomposites. Elsevier, Amsterdam, pp 367-423

113. Zamani Keteklahijani Y, Shayesteh Zeraati A, Sharif F, Roberts EPL, Sundararaj U (2020) In situ chemical polymerization of conducting polymer nanocomposites: Effect of DNA-functionalized carbon nanotubes and nitrogen-doped graphene as catalytic molecular templates. Chem Eng J 389:124500

114. Solouki Bonab V, Maxian O, Manas-Zloczower I (2019) Carbon nanofiller networks- a comparative study of networks formed by branched versus linear carbon nanotubes in thermoplastic polyurethane. Polymer 175:227-234

115. Redaelli F, Sorbona M, Rossi F (2017) 10-Synthesis and processing of hydrogels for medical applications. In: Perale G, Hilborn J 
(eds) Bioresorbable polymers for biomedical applications. Woodhead Publishing, Cambridge, pp 205-228

116. Segarra-Maset MD, Nebot VJ, Miravet JF, Escuder B (2013) Control of molecular gelation by chemical stimuli. Chem Soc Rev 42(17):7086-7098

117. Han J, Wang H, Yue Y, Mei C, Chen J, Huang C, Wu Q, Xu X (2019) A self-healable and highly flexible supercapacitor integrated by dynamically cross-linked electro-conductive hydrogels based on nanocellulose-templated carbon nanotubes embedded in a viscoelastic polymer network. Carbon 149:1-18

118. Ravanbakhsh H, Bao G, Latifi N, Mongeau LG (2019) Carbon nanotube composite hydrogels for vocal fold tissue engineering: biocompatibility, rheology, and porosity. Mater Sci Eng, C 103:109861

119. Polat TG, Ateş K, Bilgin S, Duman O, Özen Ş, Tunç S (2019) Carbon nanotube, poly(3,4-ethylenedioxythiophene):poly(styre nesulfonate) and Ag nanoparticle doped gelatin based electroactive hydrogel systems. Colloids Surf A 580:123751

120. Ahadian S, Davenport Huyer L, Estili M, Yee B, Smith N, Xu Z, Sun Y, Radisic M (2017) Moldable elastomeric polyestercarbon nanotube scaffolds for cardiac tissue engineering. Acta Biomater 52:81-91

121. Nurly H, Yan Q, Song B, Shi Y (2019) Effect of carbon nanotubes reinforcement on the polyvinyl alcohol-polyethylene glycol double-network hydrogel composites: a general approach to shape memory and printability. Eur Polymer J 110:114-122

122. Li L, Qin S, Peng J, Chen A, Nie Y, Liu T, Song K (2020) Engineering gelatin-based alginate/carbon nanotubes blend bioink for direct 3D printing of vessel constructs. Int J Biol Macromol 145:262-271

123. Patel KD, Kim T-H, Mandakhbayar N, Singh RK, Jang J-H, Lee J-H, Kim H-W (2020) Coating biopolymer nanofibers with carbon nanotubes accelerates tissue healing and bone regeneration through orchestrated cell- and tissue-regulatory responses. Acta Biomater 108:97-110

124. Fraczek-Szczypta A, Jantas D, Ciepiela F, Grzonka J (2020) Graphene oxide-conductive polymer nanocomposite coatings obtained by the EPD method as substrates for neurite outgrowth. Diam Relat Mater 102:107663

125. Huang B, Vyas C, Roberts I, Poutrel Q-A, Chiang W-H, Blaker JJ, Huang Z, Bártolo P (2019) Fabrication and characterisation of 3D printed MWCNT composite porous scaffolds for bone regeneration. Mater Sci Eng, C 98:266-278

126. Huang B, Vyas C, Byun JJ, El-Newehy M, Huang Z, Bártolo P (2020) Aligned multi-walled carbon nanotubes with nanohydroxyapatite in a 3D printed polycaprolactone scaffold stimulates osteogenic differentiation. Mater Sci Eng, C 108:110374

127. Sedaghati T, Yang SY, Mosahebi A, Alavijeh MS, Seifalian AM (2011) Nerve regeneration with aid of nanotechnology and cellular engineering. Biotechnol Appl Biochem 58(5):288-300

128. Rossignol S (2006) Plasticity of connections underlying locomotor recovery after central and/or peripheral lesions in the adult mammals. Phil Trans R Soc B Biol Sci 361(1473): 1647-1671

129. Farin A, Liu CY, Langmoen IA, Apuzzo ML (2009) Biological restoration of central nervous system architecture and function: part 3-stem cell-and cell-based applications and realities in the biological management of central nervous system disorders: traumatic vascular, and epilepsy disorders. Neurosurgery 65(5):831-859

130. Fabbro A, Prato M, Ballerini L (2013) Carbon nanotubes in neuroregeneration and repair. Adv Drug Deliv Rev 65(15):2034-2044

131. Subramanian A, Krishnan UM, Sethuraman S (2009) Development of biomaterial scaffold for nerve tissue engineering: biomaterial mediated neural regeneration. J Biomed Sci 16(1):108
132. Geller HM, Fawcett JW (2002) Building a bridge: engineering spinal cord repair. Exp Neurol 174(2):125-136

133. Mackinnon SE, Dellon AL (1990) Clinical nerve reconstruction with a bioabsorbable polyglycolic acid tube. Plast Reconstr Surg 85(3):419-424

134. Hudson TW, Evans GR, Schmidt CE (2000) Engineering strategies for peripheral nerve repair. Orthop Clin 31(3):485-497

135. Borschel GH, Kia KF, Kuzon WM, Dennis RG (2003) Mechanical properties of acellular peripheral nerve. J Surg Res 114(2):133-139

136. Arslantunali D, Budak G, Hasirci V (2014) Multiwalled CNTpHEMA composite conduit for peripheral nerve repair. J Biomed Mater Res, Part A 102(3):828-841

137. Geiger B, Spatz JP, Bershadsky AD (2009) Environmental sensing through focal adhesions. Nat Rev Mol Cell Biol 10(1):21

138. Myers JP, Santiago-Medina M, Gomez TM (2011) Regulation of axonal outgrowth and pathfinding by integrin-ECM interactions. Dev Neurobiol 71(11):901-923

139. Hu H, Ni Y, Montana V, Haddon RC, Parpura V (2004) Chemically functionalized carbon nanotubes as substrates for neuronal growth. Nano Lett 4(3):507-511

140. Galvan-Garcia P, Keefer EW, Yang F, Zhang M, Fang S, Zakhidov AA, Baughman RH, Romero MI (2007) Robust cell migration and neuronal growth on pristine carbon nanotube sheets and yarns. J Biomater Sci Polym Ed 18(10):1245-1261

141. Jan E, Kotov NA (2007) Successful differentiation of mouse neural stem cells on layer-by-layer assembled single-walled carbon nanotube composite. Nano Lett 7(5):1123-1128

142. Vicentini N, Gatti T, Salerno M, Gomez YSH, Bellon M, Gallio S, Marega C, Filippini F, Menna E (2018) Effect of different functionalized carbon nanostructures as fillers on the physical properties of biocompatible poly (l-lactic acid) composites. Mater Chem Phys 214:265-276

143. Shao H, Li T, Zhu R, Xu X, Yu J, Chen S, Song L, Ramakrishna S, Lei Z, Ruan Y (2018) Carbon nanotube multilayered nanocomposites as multifunctional substrates for actuating neuronal differentiation and functions of neural stem cells. Biomaterials. https://doi.org/10.1016/j.biomaterials.2018.05.028

144. Wu S, Duan B, Lu A, Wang Y, Ye Q, Zhang L (2017) Biocompatible chitin/carbon nanotubes composite hydrogels as neuronal growth substrates. Carbohyd Polym 174:830-840

145. Liu X, Miller AL II, Park S, Waletzki BE, Terzic A, Yaszemski MJ, Lu L (2016) Covalent crosslinking of graphene oxide and carbon nanotube into hydrogels enhances nerve cell responses. J Mater Chem B 4(43):6930-6941

146. Salehi M, Naseri-Nosar M, Ebrahimi-Barough S, Nourani M, Khojasteh A, Hamidieh AA, Amani A, Farzamfar S, Ai J (2018) Sciatic nerve regeneration by transplantation of Schwann cells via erythropoietin controlled-releasing polylactic acid/multiwalled carbon nanotubes/gelatin nanofibrils neural guidance conduit. J Biomed Mater Res B Appl Biomater 106(4):1463-1476

147. Ahn H-S, Hwang J-Y, Kim MS, Lee J-Y, Kim J-W, Kim H-S, Shin US, Knowles JC, Kim H-W, Hyun JK (2015) Carbon-nanotubeinterfaced glass fiber scaffold for regeneration of transected sciatic nerve. Acta Biomater 13:324-334

148. Xia Y, Li S, Nie C, Zhang J, Zhou S, Yang H, Li M, Li W, Cheng C, Haag R (2019) A multivalent polyanion-dispersed carbon nanotube toward highly bioactive nanostructured fibrous stem cell scaffolds. Appl Mater Today 16:518-528

149. Serrano MC, Nardecchia S, García-Rama C, Ferrer ML, Collazos-Castro JE, del Monte F, Gutiérrez MC (2014) Chondroitin sulphate-based 3D scaffolds containing MWCNTs for nervous tissue repair. Biomaterials 35(5):1543-1551

150. Lee S-J, Zhu W, Nowicki M, Lee G, Heo DN, Kim J, Zuo YY, Zhang LG (2018) 3D printing nano conductive multi-walled 
carbon nanotube scaffolds for nerve regeneration. J Neural Eng 15(1):016018

151. Gupta P, Sharan S, Roy P, Lahiri D (2015) Aligned carbon nanotube reinforced polymeric scaffolds with electrical cues for neural tissue regeneration. Carbon 95:715-724

152. Shrestha S, Shrestha BK, Kim JI, Ko SW, Park CH, Kim CS (2018) Electrodeless coating polypyrrole on chitosan grafted polyurethane with functionalized multiwall carbon nanotubes electrospun scaffold for nerve tissue engineering. Carbon $136: 430-443$

153. Koppes A, Keating K, McGregor A, Koppes R, Kearns K, Ziemba A, McKay C, Zuidema J, Rivet C, Gilbert R (2016) Robust neurite extension following exogenous electrical stimulation within single walled carbon nanotube-composite hydrogels. Acta Biomater 39:34-43

154. Wang J, Tian L, Chen N, Ramakrishna S, Mo X (2018) The cellular response of nerve cells on poly-l-lysine coated PLGAMWCNTs aligned nanofibers under electrical stimulation. Mater Sci Eng, C 91:715-726

155. Dozois MD, Bahlmann LC, Zilberman Y, Tang XS (2017) Carbon nanomaterial-enhanced scaffolds for the creation of cardiac tissue constructs: A new frontier in cardiac tissue engineering. Carbon 120:338-349

156. Braunwald E (2013) Heart failure, JACC. Heart Fail 1(1):1-20

157. Johnson TD, Christman KL (2013) Injectable hydrogel therapies and their delivery strategies for treating myocardial infarction. Expert Opin Drug Deliv 10(1):59-72

158. Hirt MN, Hansen A, Eschenhagen T (2014) Cardiac tissue engineering: state of the art. Circ Res 114(2):354-367

159. Mehra MR, Stewart GC, Uber PA (2014) The vexing problem of thrombosis in long-term mechanical circulatory support. J Heart Lung Transplant 33(1):1-11

160. Louis Jeune V, Joergensen JA, Hajjar RJ, Weber T (2013) Preexisting anti-adeno-associated virus antibodies as a challenge in AAV gene therapy. Hum Gene Ther Methods 24(2):59-67

161. Braunwald E (2015) The war against heart failure: the Lancet lecture. Lancet 385(9970):812-824

162. Nam Y-J, Song K, Olson EN (2013) Heart repair by cardiac reprogramming. Nat Med 19(4):413

163. Fu J-D, Srivastava D (2015) Direct reprogramming of fibroblasts into cardiomyocytes for cardiac regenerative medicine. Circ $\mathbf{J}$ 79(2):245-254

164. Zhou Y, Wang L, Vaseghi HR, Liu Z, Lu R, Alimohamadi S, Yin C, Fu J-D, Wang GG, Liu J (2016) Bmil is a key epigenetic barrier to direct cardiac reprogramming. Cell Stem Cell 18(3):382-395

165. Chien KR, Domian IJ, Parker KK (2008) Cardiogenesis and the complex biology of regenerative cardiovascular medicine. Science 322(5907):1494-1497

166. Severs N (1990) The cardiac gap junction and intercalated disc. Int J Cardiol 26(2):137-173

167. Meng X, Stout DA, Sun L, Beingessner RL, Fenniri H, Webster TJ (2013) Novel injectable biomimetic hydrogels with carbon nanofibers and self assembled rosette nanotubes for myocardial applications. J Biomed Mater Res, Part A 101(4):1095-1102

168. Castilho M, Hochleitner G, Wilson W, Rietbergen B, Dalton PD, Groll J, Malda J, Ito K (2018) Mechanical behavior of a soft hydrogel reinforced with three-dimensional printed microfibre scaffolds. Sci Rep 8(1):1245

169. You J-O, Rafat M, Ye GJ, Auguste DT (2011) Nanoengineering the heart: conductive scaffolds enhance connexin 43 expression. Nano Lett 11(9):3643-3648

170. Jana S, Tefft B, Spoon D, Simari R (2014) Scaffolds for tissue engineering of cardiac valves. Acta Biomater 10(7):2877-2893
171. Hasan A, Soliman S, El Hajj F, Tseng Y-T, Yalcin HC, Marei HE (2018) Fabrication and in vitro characterization of a tissue engineered PCL-PLLA heart valve. Sci Rep 8(1):8187

172. Pok S, Vitale F, Eichmann SL, Benavides OM, Pasquali M, Jacot JG (2014) Biocompatible carbon nanotube-chitosan scaffold matching the electrical conductivity of the heart. ACS Nano 8(10):9822-9832

173. Li X, Zhou J, Liu Z, Chen J, Lü S, Sun H, Li J, Lin Q, Yang B, Duan C (2014) A PNIPAAm-based thermosensitive hydrogel containing SWCNTs for stem cell transplantation in myocardial repair. Biomaterials 35(22):5679-5688

174. Wickham AM, Islam MM, Mondal D, Phopase J, Sadhu V, Tamás É, Polisetti N, Richter-Dahlfors A, Liedberg B, Griffith M (2014) Polycaprolactone-thiophene-conjugated carbon nanotube meshes as scaffolds for cardiac progenitor cells. J Biomed Mater Res B Appl Biomater 102(7):1553-1561

175. Liu Y, Liang X, Wang S, Hu K (2016) Electrospun poly (lacticco-glycolic acid)/multiwalled carbon nanotube nanofibers for cardiac tissue engineering. J Biomater Tissue Eng 6(9):719-728

176. Sun H, Lü S, Jiang X-X, Li X, Li H, Lin Q, Mou Y, Zhao Y, Han Y, Zhou J (2015) Carbon nanotubes enhance intercalated disc assembly in cardiac myocytes via the $\beta 1$-integrinmediated signaling pathway. Biomaterials 55:84-95

177. Ross RS, Borg TK (2001) Integrins and the myocardium. Circ Res 88(11):1112-1119

178. Israeli-Rosenberg S, Manso AM, Okada H, Ross RS (2014) Integrins and integrin-associated proteins in the cardiac myocyte. Circ Res 114(3):572-586

179. Shin SR, Jung SM, Zalabany M, Kim K, Zorlutuna P, Kim SB, Nikkhah M, Khabiry M, Azize M, Kong J (2013) Carbonnanotube-embedded hydrogel sheets for engineering cardiac constructs and bioactuators. ACS Nano 7(3):2369-2380

180. Mombini S, Mohammadnejad J, Bakhshandeh B, Narmani A, Nourmohammadi J, Vahdat S, Zirak S (2019) Chitosan-PVACNT nanofibers as electrically conductive scaffolds for cardiovascular tissue engineering. Int J Biol Macromol 140:278-287

181. Yu H, Zhao H, Huang C, Du Y (2017) Mechanically and electrically enhanced CNT-collagen hydrogels as potential scaffolds for engineered cardiac constructs. ACS Biomater Sci Eng 3(11):3017-3021

182. Izadifar M, Chapman D, Babyn P, Chen X, Kelly ME (2018) UV-assisted 3D bioprinting of nanoreinforced hybrid cardiac patch for myocardial tissue engineering. Tissue Eng Part C Methods 24(2):74-88

183. Dorati R, Colonna C, Genta I, Conti B (2011) Polymer scaffolds for bone tissue regeneration, Active implants and scaffolds for tissue regeneration. Springer, Berlin, pp 259-285

184. Lee J, Farag MM, Park EK, Lim J, Yun H-S (2014) A simultaneous process of $3 \mathrm{D}$ magnesium phosphate scaffold fabrication and bioactive substance loading for hard tissue regeneration. Mater Sci Eng, C 36:252-260

185. Oryan A, Alidadi S, Moshiri A, Maffulli N (2014) Bone regenerative medicine: classic options, novel strategies, and future directions. J Orthop Surg Res 9(1):18

186. Sanz M, Vignoletti F (2015) Key aspects on the use of bone substitutes for bone regeneration of edentulous ridges. Dent Mater 31(6):640-647

187. Denry I, Kuhn LT (2016) Design and characterization of calcium phosphate ceramic scaffolds for bone tissue engineering. Dent Mater 32(1):43-53

188. Tanaka M, Sato Y, Haniu H, Nomura H, Kobayashi S, Takanashi S, Okamoto M, Takizawa T, Aoki K, Usui Y (2017) A three-dimensional block structure consisting exclusively of carbon nanotubes serving as bone regeneration scaffold and as bone defect filler. PLoS ONE 12(2):e0172601 
189. Tanaka M, Sato Y, Zhang M, Haniu H, Okamoto M, Aoki K, Takizawa T, Yoshida K, Sobajima A, Kamanaka T (2017) In vitro and in vivo evaluation of a three-dimensional porous multi-walled carbon nanotube scaffold for bone regeneration. Nanomaterials 7(2):46

190. Oyefusi A, Olanipekun O, Neelgund GM, Peterson D, Stone JM, Williams E, Carson L, Regisford G, Oki A (2014) Hydroxyapatite grafted carbon nanotubes and graphene nanosheets: promising bone implant materials. Spectrochim Acta Part A Mol Biomol Spectrosc 132:410-416

191. Liu J, Gao C, Feng P, Xiao T, Shuai C, Peng S (2015) A bioactive glass nanocomposite scaffold toughed by multi-wall carbon nanotubes for tissue engineering. J Ceram Soc Jpn 123(1438):485-491

192. Khalid P, Hussain M, Rekha P, Arun A (2015) Carbon nanotube-reinforced hydroxyapatite composite and their interaction with human osteoblast in vitro. Hum Exp Toxicol 34(5):548-556

193. Huang B, Caetano G, Vyas C, Blaker JJ, Diver C, Bártolo P (2018) Polymer-ceramic composite scaffolds: the effect of hydroxyapatite and $\beta$-tri-calcium phosphate. Materials 11(1):129

194. Gupta A, Main BJ, Taylor BL, Gupta M, Whitworth CA, Cady C, Freeman JW, El-Amin SF (2014) In vitro evaluation of three-dimensional single-walled carbon nanotube composites for bone tissue engineering. J Biomed Mater Res, Part A 102(11):4118-4126

195. Gupta A, Liberati T, Verhulst S, Main B, Roberts M, Potty A, Pylawka T, El-Amin S III (2015) Biocompatibility of singlewalled carbon nanotube composites for bone regeneration. Bone Jt Res 4(5):70-77

196. Flores-Cedillo M, Alvarado-Estrada K, Pozos-Guillén A, Murguía-Ibarra J, Vidal M, Cervantes-Uc J, Rosales-Ibáñez R, Cauich-Rodríguez J (2016) Multiwall carbon nanotubes/polycaprolactone scaffolds seeded with human dental pulp stem cells for bone tissue regeneration. J Mater Sci Mater Med 27(2):35

197. Abdal-hay A, Taha M, Mousa HM, Bartnikowski M, Hassan ML, Dewidar M, Ivanovski S (2019) Engineering of electricallyconductive poly( $\varepsilon$-caprolactone)/ multi-walled carbon nanotubes composite nanofibers for tissue engineering applications. Ceram Int 45(12):15736-15740

198. Cancian G, Tozzi G, Hussain AAB, De Mori A, Roldo M (2016) Carbon nanotubes play an important role in the spatial arrangement of calcium deposits in hydrogels for bone regeneration. $\mathbf{J}$ Mater Sci Mater Med 27(8):126
199. Mesgar AS, Mohammadi Z, Khosrovan S (2018) Improvement of mechanical properties and in vitro bioactivity of freeze-dried gelatin/chitosan scaffolds by functionalized carbon nanotubes. Int J Polym Mater Polym Biomater 67(5):267-276

200. Shokri S, Movahedi B, Rafieinia M, Salehi H (2015) A new approach to fabrication of $\mathrm{Cs} / \mathrm{BG} / \mathrm{CNT}$ nanocomposite scaffold towards bone tissue engineering and evaluation of its properties. Appl Surf Sci 357:1758-1764

201. Duan S, Yang X, Mei F, Tang Y, Li X, Shi Y, Mao J, Zhang H, Cai Q (2015) Enhanced osteogenic differentiation of mesenchymal stem cells on poly (l-lactide) nanofibrous scaffolds containing carbon nanomaterials. J Biomed Mater Res, Part A 103(4):1424-1435

202. Jing Z, Wu Y, Su W, Tian M, Jiang W, Cao L, Zhao L, Zhao Z (2017) Carbon nanotube reinforced collagen/hydroxyapatite scaffolds improve bone tissue formation in vitro and in vivo. Ann Biomed Eng 45(9):2075-2087

203. Wang C, Yu B, Fan Y, Ormsby RW, McCarthy HO, Dunne N, Li X (2019) Incorporation of multi-walled carbon nanotubes to PMMA bone cement improves cytocompatibility and osseointegration. Mater Sci Eng, C 103:109823

204. Świętek M, Brož A, Tarasiuk J, Wroński S, Tokarz W, Kozieł A, Błażewicz M, Bačáková L (2019) Carbon nanotube/iron oxide hybrid particles and their PCL-based 3D composites for potential bone regeneration. Mater Sci Eng, C 104:109913

205. Jakus AE, Secor EB, Rutz AL, Jordan SW, Hersam MC, Shah RN (2015) Three-dimensional printing of high-content graphene scaffolds for electronic and biomedical applications. ACS Nano 9(4):4636-4648

206. Xiong W, Liu Y, Jiang LJ, Zhou YS, Li DW, Jiang L, Silvain J-F, Lu YF (2016) Laser-directed assembly of aligned carbon nanotubes in three dimensions for multifunctional device fabrication. Adv Mater 28(10):2002-2009

207. Esrafilzadeh D, Jalili R, Stewart EM, Aboutalebi SH, Razal JM, Moulton SE, Wallace GG (2016) High-performance multifunctional graphene-PLGA fibers: toward biomimetic and conducting 3D scaffolds. Adv Func Mater 26(18):3105-3117

Publisher's Note Springer Nature remains neutral with regard to jurisdictional claims in published maps and institutional affiliations. 